OPEN ACCESS

Edited by:

Stephanie DeWitte-Orr

Wilfrid Laurier University, Canada

Reviewed by:

Maria Del Mar Ortega-Villaizan,

Universidad Miguel Hernández de

Elche, Spain

Eduardo Gomez-Casado,

Instituto Nacional de Investigación y

Tecnología Agraria y Alimentaria

(INIA), Spain

*Correspondence:

Chengyu Hu

hucy2008@163.com

Specialty section

This article was submitted to

Comparative Immunology,

a section of the journal

Frontiers in Immunology

Received: 06 September 2018 Accepted: 04 March 2019

Published: 28 March 2019

Citation:

Xu X, Li M, Wu C, Li D, Jiang Z, LiU C,

Cheng B, Mao H and Hu C (2019) The

Fish-Specific Protein Kinase (PKZ)

Initiates Innate Immune Responses via

IRF3- and ISGF3-Like Mediated

Pathways. Front. Immunol. 10:582.

doi: 10.3389/fimmu.2019.00582

\section{The Fish-Specific Protein Kinase (PKZ) Initiates Innate Immune Responses via IRF3- and ISGF3-Like Mediated Pathways}

\author{
Xiaowen $X u^{1}$, Meifeng $L^{1}{ }^{1}$, Chuxin $W u^{1}$, Dongming $L i^{2}$, Zeyin Jiang ${ }^{1}$, Changxin Liu ${ }^{1}$, \\ Bo Cheng ${ }^{1}$, Huiling $\mathrm{Mao}^{1}$ and Chengyu $\mathrm{Hu}^{1 *}$ \\ ${ }^{1}$ College of Life Science, Nanchang University, Nanchang, China, ${ }^{2}$ Fuzhou Medical College, Nanchang University, \\ Fuzhou, China
}

PKZ is a fish-specific protein kinase containing $Z \alpha$ domains. PKZ is known to induce apoptosis through phosphorylating eukaryotic initiation factor $2 \alpha$ kinase (elF2 $\alpha$ ) in the same way as double-stranded RNA-dependent protein kinase (PKR), but its exact role in detecting pathogens remains to be fully elucidated. Herein, we have found that PKZ acts as a fish-specific DNA sensor by initiating IFN expression through IRF3- or ISGF3-like mediated pathways. The expression pattern of $P K Z$ is similar to those of innate immunity mediators stimulated by poly (dA:dT) and poly (dG:dC). DNA-PKZ interaction can enhance PKZ phosphorylation and dimerization in vitro. These findings indicate that PKZ participates in cytoplasmic DNA-mediated signaling. Subcellular localization assays have also shown that PKZ is located in the cytoplasm, which suggests that PKZ acts as a cytoplasmic PRR. Meanwhile, co-IP assays have shown that PKZ can separately interact with IRF3, STING, ZDHHC1, elF2 $\alpha$, IRF9, and STAT2. Further investigations have revealed that PKZ can activate IRF3 and STAT2; and that IRF3-dependent and ISGF3-like dependent mediators are critical for PKZ-induced IFN expression. These results demonstrate that PKZ acts as a special DNA pattern-recognition receptor, and that PKZ can trigger immune responses through IRF3-mediated or ISGF3-like mediated pathways in fish.

Keywords: PKZ, PRR, IRF3-mediated and ISGF3-like mediated pathways, innate immunity, teleost

\section{HIGHLIGHTS}

- The expression pattern of PKZ is similar to those of IRF3-dependent and ISGF3-like-dependent mediators.

- In vitro, PKZ can be activated by poly (dA:dT)- or poly (dG:dC)-PKZ interaction, but PKZ cannot interact with RNA.

- PKZ activates IFN expression through IRF3- or ISGF3-like-dependent pathway. 


\section{INTRODUCTION}

Innate immunity is the first defense line for vertebrates, especially lower vertebrates, to fight off invading pathogens $(1,2)$. Patternrecognition receptors (PRRs) that recognize pathogen-associated molecular patterns (PAMPs) play vital roles in initiating IFN signaling pathways (3-5). In recent years, many complicated and effective PRRs have been identified in mammals. A few toll-likereceptors (TLR) and RIG-I-like receptors (RLR) are known to detect bacterial and viral RNAs $(6,7)$. TLR3 recognizes doublestranded RNA (dsRNA), and then triggers IFN- $\beta$ expression by activating interferon transcription factor 3 (IRF3) and nuclear factor $\kappa B(\mathrm{NF}-\kappa \mathrm{B})(8,9)$. RLRs (RIG-I and MDA5) detect cytosolic RNA via the adaptor protein IPS- 1 and activate IFN- $\beta$ signaling pathways (10).

In addition to the RNA sensors described above, a number of intracellular DNA sensors have been confirmed in recent times, such as absent in melanoma 2 (AIM2) (11), DNAdependent activator of IFN-regulatory factors (DAI) (12), IFNinducible protein 16 (IFI16) (13), DEAD (Asp-Glu-Ala-Asp) box polypeptide 41 (DDX41) (14), RNA polymerase III (15), and Cyclic GMP-AMP synthase (cGAS) (16). These proteins are important in responding to various DNA infections. For example, IFI16 is a sensor for HIV DNA through interaction with stimulator of IFN gene (STING), and is also important in inducing IFN- $\beta$ reactions in human macrophages (13). Cyclic GMP-AMP synthase (cGAS) is known to detect cytosolic DNA in various cell types (16). Recognition of viral DNA by cGAS induces the synthesis first of the second message cGAMP from ATP and GTP, and then of cGAMP which binds to STING; and STING enhances IRF3 phosphorylation by TBK1, thus activating downstream genes (17-21).

In recent years, much progress has been made in the study of fish PRRs. Along with the discovery of RNA sensors in mammals, RLRs (RIG-I, MDA5, and LGP2) and TLRs, which are involved in dsRNA recognition, were also identified in teleost fish (22-27). While the findings on RNA-recognizing PRRs in fish are quite clear, those on DNA-recognizing PRRs are ambiguous. A novel member of vertebrate eIF2 $\alpha$ kinase, named PKZ (protein kinase containing $\mathrm{Z} \alpha$ binding domains), has been identified exclusively in fish (28-30). The $\mathrm{Z} \alpha$ binding domains of fish PKZ similar to the DNA sensors in mammals (28-30). This suggests PKZ might be a special DNA sensor in fish (31). Recent studies have demonstrated that fish PKZ can specifically respond to poly (dG:dC), then phosphorylate eIF $2 \alpha$, and finally lead to apoptosis $(30,32,33)$.

The present study has demonstrated that the expression profile of $P K Z$ is similar to those of IFN response mediators; that PKZ can specifically recognize poly (dA:dT) and poly (dG:dC) but not poly I:C (dsRNA analog) in vitro; and that PKZ is located in the cytoplasm and is a basic factor in DNA recognition. As well, when cells are stimulated by invading DNA molecules, PKZ can interact with and activate the mediators in the IRF3-dependent or ISGF3-like dependent pathway. Our findings suggest that PKZ performs as a special DNA-sensing receptor and triggers immune responses through the IRF3-dependent or ISGF3-like dependent pathway.

\section{MATERIALS AND METHODS}

\section{Cells and Virus Analogs}

Grass carp (Ctenopharyngodon idellus) ovary cells (CO) and C. idellus kidney cells (CIK) were cultured in medium 199 supplemented with $10 \%$ FCS at $28^{\circ} \mathrm{C}$. Human Embryonic Kidney 293T cells (HEK-293T) were maintained at $37^{\circ} \mathrm{C}$ under $5.0 \% \mathrm{CO}_{2}$ in DMEM supplemented with 10\% FCS. CO cells are superior to CIK cells due to its stronger ability of expression and better cell morphology. In addition, HEK-293T cells were used instead of $\mathrm{CIK}$ and $\mathrm{CO}$ cells in immunoprecipitation assay because of their super-high transfection efficiency.

ISD-PS (biotin tagged ISD-PS), poly (dA:dT) [biotin tagged poly (dA:dT)] and poly (dG:dC) [biotin tagged poly (dG:dC)] were all synthesized by Sangon Biotech (China) and their sequences were presented in Table 1. ISD-PS is an RNA analog carrying a biotin tag (34). Poly I:C was purchased from Sigma (USA). The nucleic acids [poly (dA:dT), poly (dG:dC), and ISDPS] were synthesized in accordance with the manufacturer's protocols from $10 \mu \mathrm{l}$ DNA oligo, $2 \mu \mathrm{l} 10 \times$ oligo annealing buffer (100 mM Tris-HCl, pH 8.0, 10 mM EDTA, pH8.0, $1 \mathrm{M} \mathrm{NaCl}$ ), and $8 \mu \mathrm{l} \mathrm{DNase/RNase-free} \mathrm{water.} \mathrm{The} 20 \mu \mathrm{l}$ total- reaction mixture was incubated at $95^{\circ} \mathrm{C}$ for $4 \mathrm{~min}$, and then kept at room temperature for 5-10 $\mathrm{min}$.

\section{Plasmids and Recombinant Construction}

pCMV-FLAG and pcDNA3.1(+) were both purchased from Invitrogen (USA). pEGFP-C1, pGL3, and E. coli strains DH5 $\alpha$ were all bought from Promega (USA). The C. idellus open reading frames (ORFs) of PKZ, IRF3, STING, ZDHHC1, IRF9, STAT2, eIF2 $\alpha$, and ADAR1 were prepared, and each of them was separately inserted into pCMV-FLAG, pEGFP-C1, and pcDNA3.1 $(+)$ vectors to construct expression plasmids. They were used for in vitro translation, nucleic acids pull down, sublocalization, and co-IP assays. Each of the C. idellus mutants of PKZ-C (176-513 aa), PKZ-N (1-169 aa), and PKZ-198K (K198R) was separately inserted into pcDNA3.1 (+); meanwhile, each of the mutants mentioned above was also individually inserted into pCMV-FLAG (Figure 3A). All of the constructs were confirmed by DNA sequencing. The primers used for plasmid construction were given in Table 1. The plasmids, genes, types of experiment, and Genbank ID for this paper were listed in Table 2.

\section{Luciferase Activity and Quantitative RT-PCR Assays}

Each plasmid was transfected according to the FuGENE ${ }^{\circledR} 6$ (Promega, USA) protocol. Each well of 6-well plate was transfected with $2 \mu \mathrm{g}$ of plasmid, and each $10-\mathrm{cm}$ dish was transfected with $5 \mu \mathrm{g}$ of plasmid. In nucleic acid stimulation, nucleic acid $(2 \mu \mathrm{g})$ was transfected into cells. In luciferase activity assays, $0.25 \mu \mathrm{g}$ of $P K Z$-pcDNA3.1 (or basic-pcDNA3.1 plasmid), $0.25 \mu \mathrm{g}$ of IFN-pro-pGL3, and $0.025 \mu \mathrm{g}$ of pRL-TK Renilla luciferase vectors were transfected in CIK or CO cells. IFN promoter was inserted into pGL3 plasmid. As this recombinant plasmid was used in dual-luciferase activity assay, the luciferase activity of the promoter can reflect $I F N$ transcription levels. 
TABLE 1 | The nucleotide sequence of primers in this study.

\begin{tabular}{|c|c|c|}
\hline Primer name & Primer sequence $\left(5^{\prime}-3^{\prime}\right)$ & Application \\
\hline PKZ-RT-F & CACCGTGAACAGACATTTG & 不 \\
\hline PKZ-RT-R & TCCCTTACGTGTTTCTCTTC & \\
\hline STING-RT-F & ACATAGCAGGGGTACGGAAT & \\
\hline STING-RT-R & CCATGTGAATCTCTCCGTCC & \\
\hline ZDHHC1-RT-F & GTCTGTCACCTCTTCATGCA & \\
\hline ZDHHC1-RT-R & CAGGAGAGCAGAAATCACAC & \\
\hline IFN-RT-F & GTCAATGCTCTGCTTGCGAAT & Real-time PCR \\
\hline IFN-RT-R & CAAGAAACTTCACСTGGTCCT & \\
\hline TBK1-RT-F & GAGACATCAAGCCAGGGAAC & \\
\hline TBK1-RT-R & AAAACGTGACTCCGATGCTC & \\
\hline IPS-1-RT-F & AATTGGCTCGCTITCGTCA & \\
\hline IPS1-RT-R & TCATCAGCCAGTTCCCTATGT & \\
\hline IRF3-RT-F & TCCAGGCCAAGCATACGAA & \\
\hline IRF3-RT-R & CCATTTGCAACAGCCATCAT & $\underline{\Downarrow}$ \\
\hline IRF3-ORF-F & ATGACCCATCCAAAACCGCT & $\bar{\uparrow}$ \\
\hline IRF3-ORF-R & TCACTTGGTGTCACACAACTC & \\
\hline ZDHHC1-ORF-F & ATGGACGTCTGCAGTAAGAAC & \\
\hline ZDHHC1-ORF-R & TGTGGTGCTGGTGTCAATG & \\
\hline STING-ORF-F & AATGTGTGGTGTGATCGGAG & \\
\hline STING-ORF-R & CGAATAATCAGTAGTCTCCTCAGG & \\
\hline ADAR1-ORF-F & ATGAGCAGAGGTAGAGGAGGGTा & \\
\hline ADAR1-ORF-R & CTAAAAGCCCTGTGCTGCAGA & \\
\hline PKZ-ORF-F & АTGTCTGCCGAAACTCAAATG & Eukaryotic expressior \\
\hline PKZ-ORF-R & TCAAATCGTITCTGGCTTAACA & \\
\hline elF2 $\alpha$-ORF-F & ATGCCCGGACTCAGCTGTA & \\
\hline elF2 $\alpha$-ORF-R & AGCTAGTCATCAGTCTTGGCCTC & \\
\hline IRF9-ORF-F & ATGGCATCTGGAAGGATTCGT & \\
\hline IRF9-ORF-R & GGGCTITAATGTCAAGAATGCAGC & \\
\hline STAT1-ORF-F & ATGGCACTTGGAACCAGCTGC & \\
\hline STAT1-ORF-R & ACACTाTGGAGTCTTGAAACAGGG & \\
\hline STAT2-ORF-F & AGAATGACTCAGTGGGACCG & \\
\hline STAT2-ORF-R & AGGGGTCATGGATCAAATTCAGG & \\
\hline STAT6-ORF-F & ACAACAAACGCACACGGAA & \\
\hline STAT6-ORF-R & GACCGTACCTCAAAATGATGACAA & \\
\hline Poly (dA: dT) & $\begin{array}{l}\text { CTGATACTACATTGAATTCTATATATA } \\
\text { TATATATATATAGAATTCAAT }\end{array}$ & $\bar{\uparrow}$ \\
\hline Poly (dG: dC) & $\begin{array}{l}\text { GTAGTATCAGA } \\
\text { CTGATACTACATTGAATTCGCGCGC } \\
\text { GCGCGCGCGCGCGCGAATTC } \\
\text { AATGTAGTATCAGA }\end{array}$ & DNA analog \\
\hline ISD-PS & $\begin{array}{l}\text { TACAGATCTACTAGTGATCTATGAC } \\
\text { TGATCTGTACATGATCTACA }\end{array}$ & RNA analog \\
\hline siRNA-PKZ & GCCAGACUAGACCAUCCAATT & siRNA \\
\hline
\end{tabular}

In the quantitative RT-PCR assay, CIK cells were seeded in 6well plates and transfected with $2 \mu \mathrm{g}$ of poly (dA:dT) or $2 \mu \mathrm{g}$ of poly (dG:dC). After all RNA was extracted from CIK cells, qRT-PCR was also used to detect the expression levels of IFN, IPS-1, TBK1, and PKZ. Grass carp IFN expression was detected in CO cells transfected with $2 \mu \mathrm{g}$ of $P K Z$-pcDNA3.1, $2 \mu \mathrm{g}$ of IRF3-pcDNA3.1, $2 \mu \mathrm{g}$ of STING-pcDNA3.1, $2 \mu \mathrm{g}$ of ZDHHC1pcDNA3.1, $2 \mu \mathrm{g}$ of IRF9-pcDNA3.1, $2 \mu \mathrm{g}$ of STAT2-pcDNA3.1, and $2 \mu \mathrm{g}$ of empty vectors. Twenty-four hours later, the cells were transfected with $2 \mu \mathrm{g}$ of poly (dG:dC) for $6 \mathrm{~h}$.

\section{Subcellular Localization Analysis}

In subcellular localization analysis, CO cells were plated on 35 $\mathrm{cm}^{2}$ microscopic petri dishes. After $12 \mathrm{~h}$ they were transfected with PKZ-GFP, ADAR1-GFP, and GFP-C1. Twenty-four hours post transfection, the cells were washed three times with PBS, and fixed with $4 \%(\mathrm{v} / \mathrm{v})$ paraformaldehyde at room temperature for $15 \mathrm{~min}$. The cells were then dyed with DAPI $(0.1 \mu \mathrm{g} / \mathrm{ml})$ and examined under a confocal microscope (Olympus, FV1000).

\section{Nucleic Acids Pulldown Assays}

In nucleic acids pulldown assays, synthetic ISD-PS was used as RNA analog. Two microgram each of biotin-labeled ISDPS, poly (dA:dT), and poly (dG:dC) were incubated with M280 streptavidin-coupled Dynabeads (Invitrogen) for $5 \mathrm{~h}$. The unbound biotin-labeled nucleic acids were washed with $1 \times \mathrm{BW}$ buffer $(5 \mathrm{mM}$ Tris-HCl pH 7.5, $0.5 \mathrm{mM}$ EDTA, $1 \mathrm{M} \mathrm{NaCl})$ five times and immobilized on M-280 streptavidin-coupled Dynabeads (Invitrogen) at $4^{\circ} \mathrm{C}$. CO cells were plated on $10 \mathrm{~cm}$ diameter dishes and transfected with $5 \mu \mathrm{g}$ of $P K Z$-FLAG (or $P K Z$-C-FLAG or PKZ-N-FLAG) plasmids. Twenty-four hours later, the cells were stimulated with poly (dG:dC) for $12 \mathrm{~h}$. The medium was carefully removed and washed twice with PBS, and lysates were cleared by sonication and centrifugation. Cleared lysates were incubated with Dynabeads which were separately immobilized with biotin-nucleic acids (poly (dA:dT), poly (dG:dC) and ISD-PS at $4^{\circ} \mathrm{C}$ on a rotary wheel for $12 \mathrm{~h}$. The experiment was divided in two groups. In non-competitor group, lysates were incubated with Dynabeads immobilized with biotin-nucleic acids; in competitor group, lysates, and competitors were incubated with Dynabeads immobilized with biotin-nucleic acids. Ten micrograms each of non-biotin tagged nucleic acids (poly (dA:dT), poly (dG:dC), and ISD-PS) acted as competitors. Highly concentrated non-biotin tagged nucleic acids in incubations (lysates and Dynabeads immobilized with biotin-nucleic acids) will competitively interact with proteins. The unbound proteins in Dynabeads were removed by five consecutive washes with $1 \times \mathrm{BW}$ buffer. Given that the proteins can interact with nucleic acids, PKZ-FLAG can be detected in the non-competitor group and cannot be detected in the competitor group. The beads of what were eluted with $100 \mu \mathrm{l}$ of $2 \times$ SDS sample buffer by boiling for $7 \mathrm{~min}$ at $95^{\circ} \mathrm{C}$, before performing Western blot analysis.

\section{Antibodies, Western Blot, Co-immunoprecipitation (co-IP) Assays, and Analysis of Phosphorylation State}

Mouse monoclonal antibodies against FLAG and GFP were purchased from Sigma (USA) and Abmart (USA), respectively. Phospho-IRF3 (Ser 396) rabbit monoclonal antibody was purchased from Cell Signaling Technology (USA). Anti-GAPDH rabbit polyclonal antibody was purchased from CWBIO (China). Rabbit polyclonal anti-grass carp PKZ, IFN, IRF3, STING, and ZDHHC1 antisera were prepared in our lab $(33,35)$. HEK-293T cells were used in co-IP assays instead of fish cells because of their superior transfection efficiency. Co-IP assays and Western blot were performed as previously described $(36,37)$. 
TABLE 2 | The plasmids, genes, types of experiment, and genebank ID were used in the article.

\begin{tabular}{|c|c|c|c|c|}
\hline \multirow{2}{*}{$\begin{array}{l}\text { Plasmids } \\
\text { pcDNA3.1 }\end{array}$} & \multirow{2}{*}{$\begin{array}{l}\text { Genes } \\
\text { PKZ, IRF3, STING, ZDHHC1, IRF9, } \\
\text { STAT2, }\end{array}$} & \multirow{2}{*}{$\begin{array}{l}\text { Types of experiment } \\
\text { qRT-PCR, Western blot, Dual-luciferase assay, RNAi }\end{array}$} & \multicolumn{2}{|c|}{ GeneBank ID } \\
\hline & & & PKZ & GU299765.1 \\
\hline & & & PKR & JX511974.1 \\
\hline & & & IRF3 & KC898261.1 \\
\hline \multirow[t]{3}{*}{ pCMV-FLA } & PKZ, IRF3 & Western blot, DNA-pulldown, Immunoprecipitation assay & STING & KF494194.1 \\
\hline & & & $\mathrm{ZDHHC1}$ & KY680346.1 \\
\hline & & & IRF9 & KT601055.1 \\
\hline \multirow[t]{5}{*}{ pEGFP-C1 } & $\begin{array}{l}\text { PKZ, ADAR1, IRF3, STING, ZDHHC1, } \\
\text { IRF9, STAT1, STAT2, STAT6, elF2 } \alpha\end{array}$ & Subcellular localization, Immunoprecipitation assay & STAT1 & KU508677.1 \\
\hline & & & STAT2 & KT781914.1 \\
\hline & & & STAT6 & MG384738.1 \\
\hline & & & elF2 $\alpha$ & KX906957 \\
\hline & & & IFN & DQ357216.1 \\
\hline \multirow[t]{3}{*}{ pGL3 } & IFN & Dual-luciferase assay & ADAR1 & KU198336.1 \\
\hline & & & IPS-1 & KF366908.1 \\
\hline & & & TBK1 & JN704345.1 \\
\hline
\end{tabular}

In the absence of specific phospho-PKZ and phospho-STAT2 antibodies, immunoprecipitation assays were performed to study PKZ and STAT2 phosphorylation. To begin with, CO cells were transfected with $2 \mu \mathrm{g}$ of PKZ-FLAG/STAT2-GFP plasmids. Twenty-four hours later, the cells were separately stimulated with poly I:C, poly (dA:dT) and poly (dG:dC) for $12 \mathrm{~h}$. All the proteins were then harvested with lysis (Transgene, China). First, the amount of PKZ-FLAG/STAT2-GFP proteins was determined by Western blot. The concentrations of protein in lysates were determined by an Enhanced BCA Protein Assay kit (Beyotime). Then the same amount of PKZ-FLAG/STAT2GFP was immunoprecipitated from cell lysates. Finally, the phosphorylation of PKZ/STAT2 was detected with an antiphospho-Ser/Thr/Tyr antibody (AnaSpec, CA).

\section{Native PAGE}

$\mathrm{CO}$ cells were separately transfected with the negative control (4 $\mu \mathrm{g}$ of basic-pcDNA3.1), the positive control [ $4 \mu \mathrm{g}$ of poly I:C, $4 \mu \mathrm{g}$ of poly (dA:dT), $4 \mu \mathrm{g}$ of poly (dG:dC)], the experimental group (4 $\mu \mathrm{g}$ of $P K Z$-pcDNA3.1) plasmids. The lysis of total protein was studied in two groups of experiment. One group was detected in SDS-PAGE; another group detected in native PAGE. Native PAGE assays were conducted with $8 \%$ acrylamide gel without SDS. In the same way as described previously, the sample was dissolved in $5 \times$ loading buffer without SDS. The gel was run with $0.5 \%$ deoxycholate, $25 \mathrm{mM}$ Tris- $\mathrm{HCl}$ (pH 8.4), and $192 \mathrm{mM}$ glycine for $60 \mathrm{~min}$ at $35 \mathrm{~mA}$ on ice, and then immunoblotted to a nitrocellulose membrane (Millipore, USA).

\section{RNA Interference-Mediated Gene Knockdown Assays}

In the RNA interference-mediated gene knockdown assays, the specific siRNA sequence against C. idellus PKZ, IRF9, and the negative control RNA (N.C.) oligonucleotides were prepared (Shanghai GenePharma Co., Ltd.) (Table 1). The siRNA sequence against IRF3 was used as in the previous study (35). The transfection reagent, Hiperfect ${ }^{\circledR}$ (Qiagen, Germany), has been widely used in our previous study (35). The transfection was carried out according to the manufacturer's protocol and instructions.

\section{Data Analysis}

Statistical analysis of qRT-PCR was performed and graphs were prepared using Microsoft excel. The Gray value of western blot was analyzed and confocal images were made by image J. The diagram of signaling pathway was constructed with the Portable Pathway Builder Tool 2.0. Data analysis of qRT-PCR and dualluciferase assay were both presented using the unpaired twotailed $t$-test, and $p<0.05$ were considered statistically significant $\left({ }^{*} p<0.05,{ }^{* *} p<0.01\right)$.

\section{RESULTS}

\section{PKZ and Some Mediators of Immune Responses Are Up-Regulated Under Stimulation With Poly (dA:dT) and Poly (dG:dC)}

To delineate the functional link of PKZ with IFN, IRF3, STING, ZDHHC1, IPS-1, and TBK1, their expression patterns in CIK cells were identified under the same conditions. PKZ, IFN, IRF3, STING, and ZDHHC1 were upregulated under stimulation with poly (dA:dT) (Figure 1A) and poly (dG:dC) (Figure 1B) at mRNA level. It was also found that when the cells were stimulated with poly (dA:dT) and poly (dG:dC), $P K Z$ transcripts showed a significant increase at the early phase of stimulation, and the transcripts of STING, IRF3, and ZDHHC1 showed similar increases. The increase in transcripts of IFN, IPS-1, and TBK1 appeared to be biphasic under stimulation with poly (dA: dT) rather than poly (dG: dC). PKR acted as a negative control in all cases. These results indicate that fish 


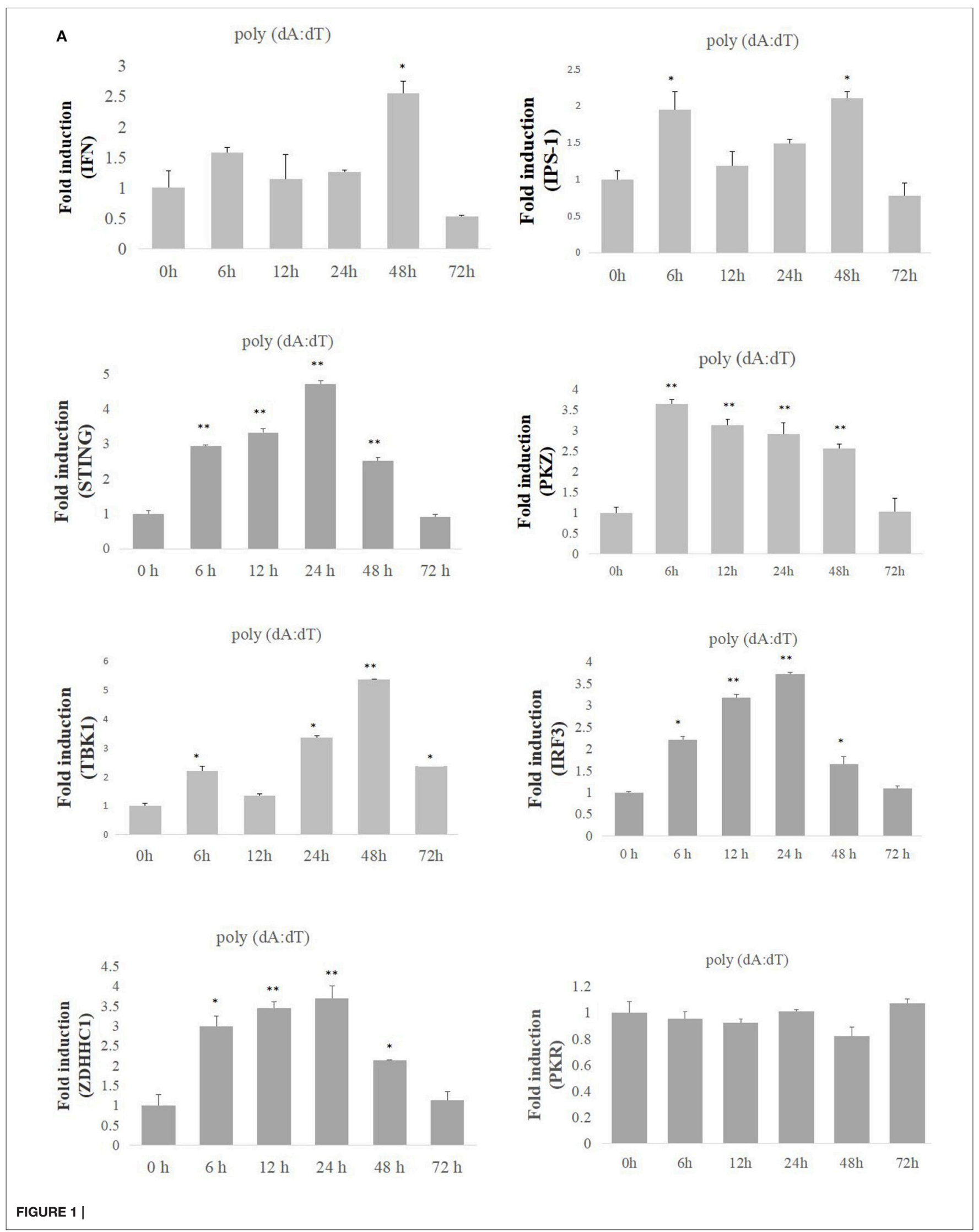




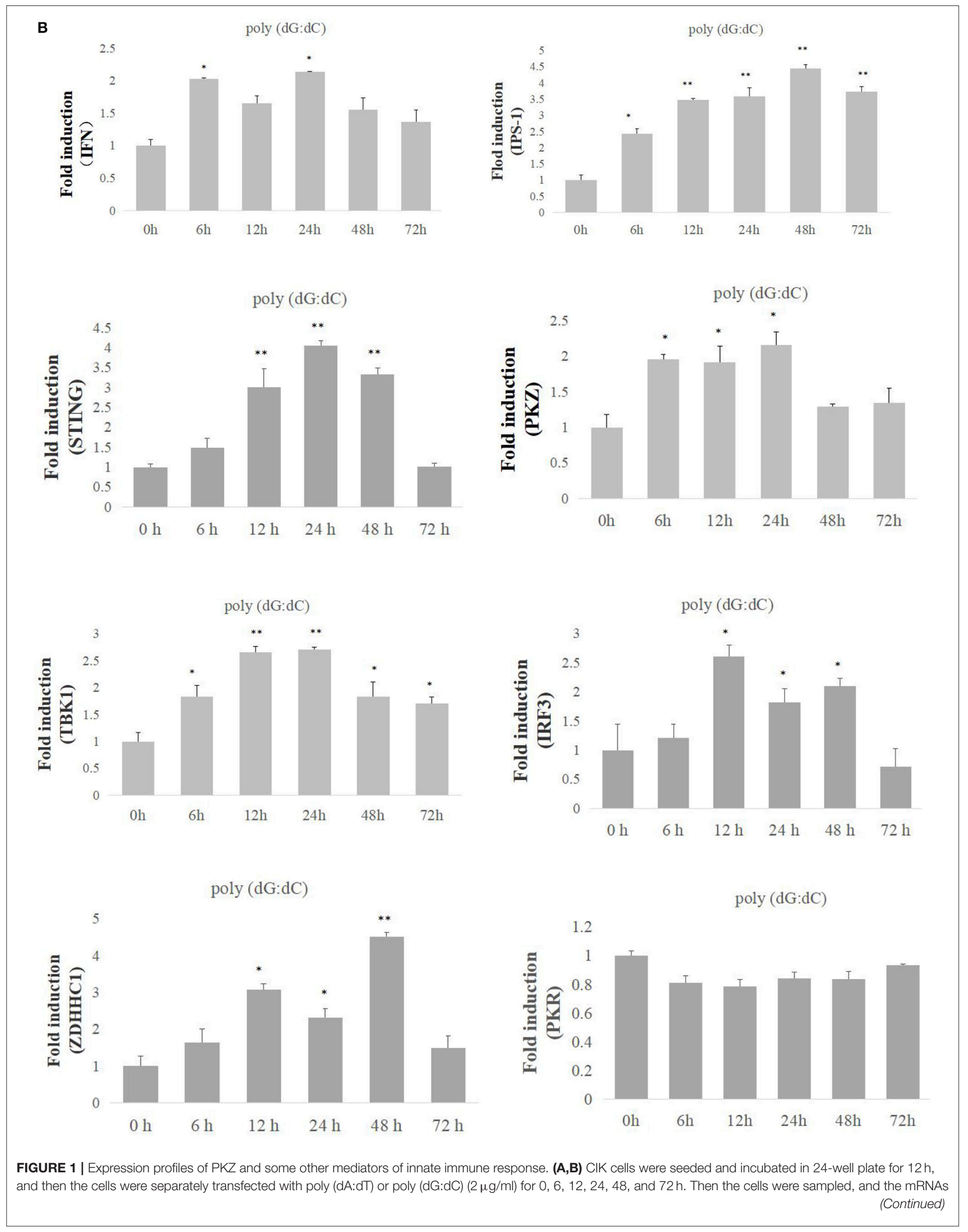


FIGURE 1 I of IFN, IPS-1, STING, PKZ, TBK1, IRF3, and ZDHHC1 were detected by qRT-PCR. The mRNA expression levels of target genes were normalized relative to the reference gene $\beta$-actin. The groups of $0 \mathrm{~h}$ were controls, and the others $(6,12,24,48,72 \mathrm{~h})$ were experimental groups. Data represent mean $\pm \mathrm{SD}(n=3)$ of three experiments and were tested for statistical significance using unpaired two-tailed $t$-test ${ }^{*} p<0.05$, ${ }^{* *} p<0.01$. The asterisk above the bracket indicated statistical significance between the control groups with experimental group.

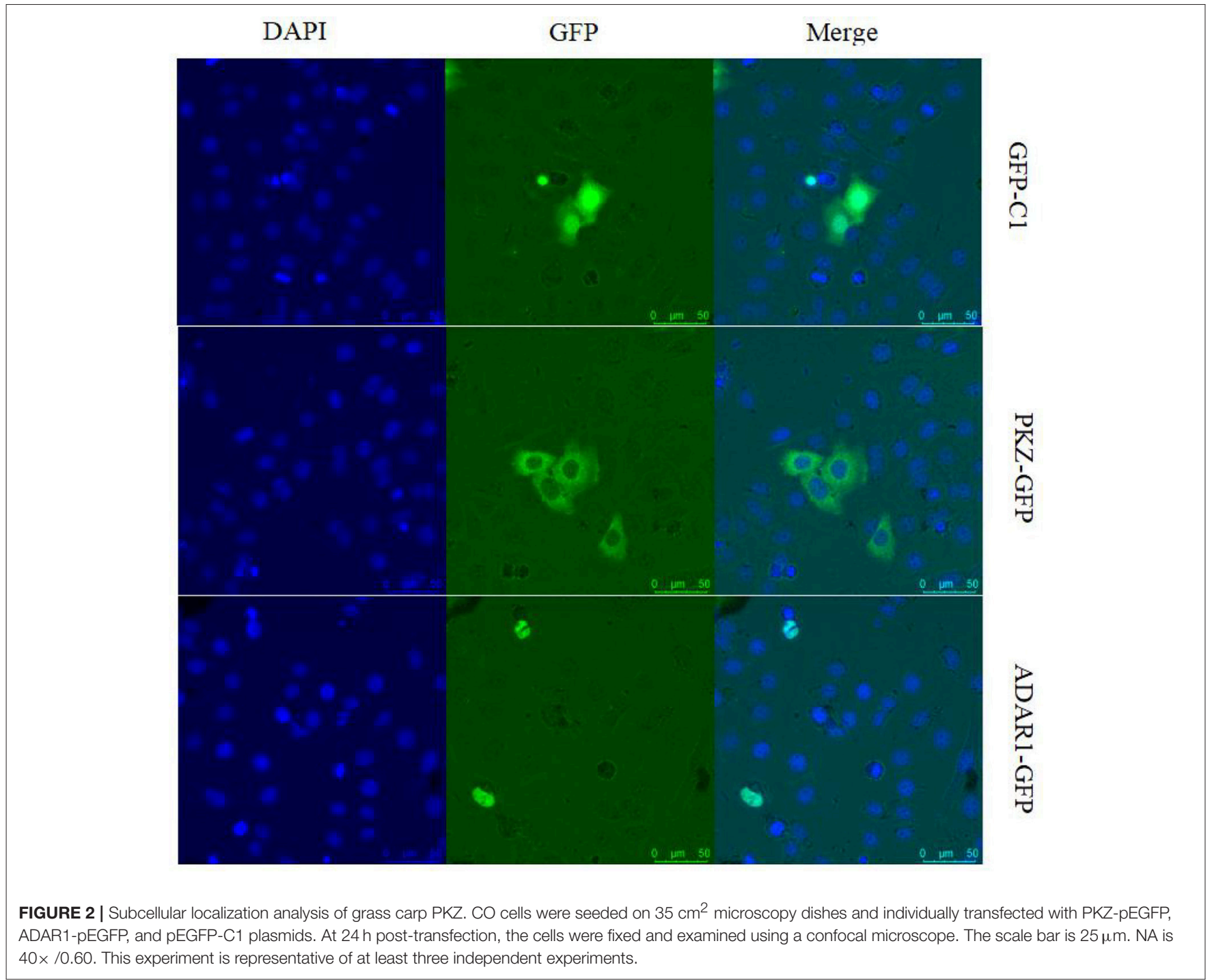

PKZ responds to poly (dA:dT) and poly (dG:dC) stimulations, just like some well-known mediators of immune response. PKZ is closely related to innate immune activity and may act as an up-stream protein under stimulation with poly (dA:dT) or poly (dG:dC).

\section{PKZ Is Located in the Cytoplasm}

It is necessary to determine the location of PKZ for its recognition of viral nucleic acids in fish cells. The plasmids PKZ-GFP and ADAR1-GFP were separately transfected into CO cells. Confocal microscopic detection suggests that PKZ-GFP is located in the cytoplasm; however, ADAR1-GFP (another Z $\alpha$ protein, used as a control) is located in the nuclear (Figure 2).

\section{PKZ Can Bind to Both Poly (dA:dT) and Poly (dG: $\mathrm{dC})$ in vitro}

PKZ has two Z $\alpha$ domains at its $\mathrm{N}$-terminus and 11 conserved eIF2 $\alpha$ kinase catalytic sub-domains at its C-terminus (Figure 3A). A series of PKZ protein mutants were constructed, including C-terminus of PKZ (PKZ-C-pcDNA3.1/FLAG), Nterminus of PKZ (PKZ-N-pcDNA3.1/FLAG), and Lys ${ }^{198}$ mutant of PKZ(PKZ-198K-pcDNA3.1/FLAG) and these were used for subsequent experiments (Figure 3A). It is known that the Lys ${ }^{198}$ mutant of PKZ lacks kinase activity $(31,33)$. To investigate the compatibility of PKZ with nucleic acids, nucleic acid pulldown assays were performed by incubating biotin-labeled DNA with PKZ protein. In this assay, non-biotin tagged nucleic acids [poly 


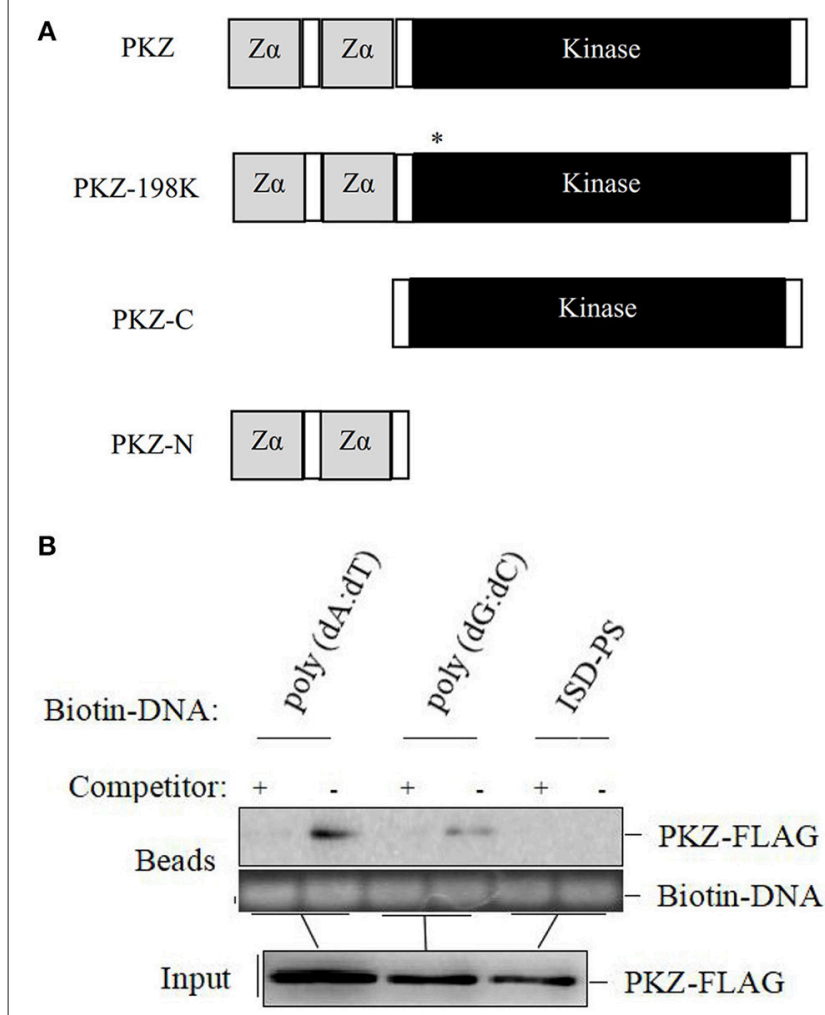

C
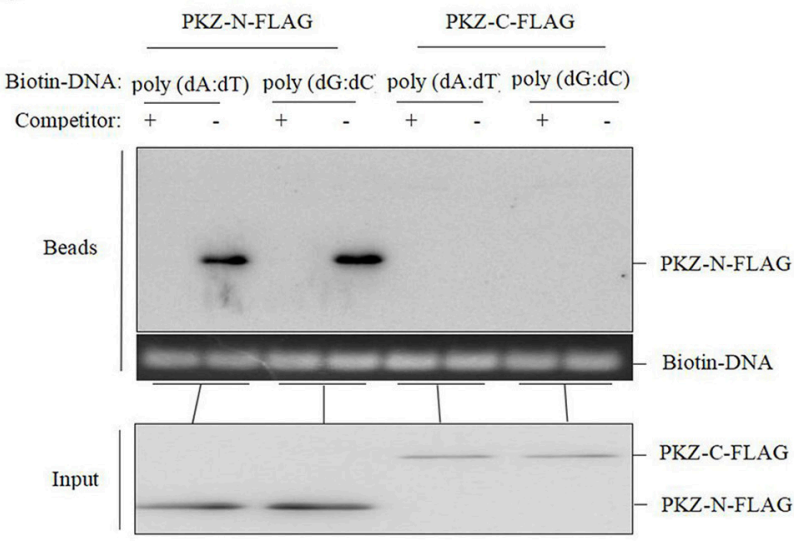

FIGURE 3 | PKZ binds to poly (dA:dT) and poly (dG:dC) in vitro. (A) PKZ and the mutants. (B) $\mathrm{CO}$ cells were seeded on $10 \mathrm{~cm}$ diameter dishes and transfected with PKZ-FLAG, at $24 \mathrm{~h}$ post-transfection, cells were harvested, a total of $1 \%$ of PKZ-FLAG containing cell lysates was loaded as input, and the rest of lysates incubated with Dynabeads were separately immobilized with 2 $\mu \mathrm{g}$ of biotin-nucleic acids (poly (dA:dT), poly (dG:dC) and ISD-PS), and $10 \mu \mathrm{g}$ of non-biotin tagged nucleic acids acted as competitors. The DNA in Dynabeads was detected in agarose gel. (C) PKZ mutants (PKZ-C-FLAG and PKZ-N-FLAG) were transfected into $\mathrm{CO}$ cells, at $24 \mathrm{~h}$ post-transfection, cells were harvested, a total of $1 \%$ of PKZ-FLAG containing cell lysates was loaded as input, and the rest of lysates incubated with Dynabeads were individually immobilized with biotin-nucleic acids (poly (dA:dT) and poly (dG:dC), and 10 $\mu \mathrm{g}$ of non-biotin tagged nucleic acids acted as competitors. The DNA in Dynabeads were examined in agarose gel. The molecular masses of PKZ-FLAG, PKZ-C-FLAG, and PKZ-N-FLAG are 67, 45, and 25 KD, respectively. Each Western blot is representative of at least three independent experiments.
(dA:dT), poly (dG:dC), and ISD-PS] acted as competitors. High concentrations of non-biotin tagged nucleic acids in incubations (lysates and Dynabeads immobilized with biotin-nucleic acids) will result in competitive interaction with proteins. Qualitative analysis of nucleic acids-bound protein with ISD-PS being used as a negative control (Figure 3B) showed that PKZ-FLAG effectively binds to poly (dA:dT) and poly (dG:dC), but not to ISD-PS (RNA analog). While $\mathrm{Z} \alpha$ domains (PKZ-N terminus) can combine with both poly (dA:dT) and poly (dG:dC), eIF2 $\alpha$ kinase catalytic sub-domain (PKZ-C terminus) cannot with either of them (Figure 3C). These results indicate that fish PKZ can recognize and interact with DNA by its Z $\alpha$ domain.

\section{PKZ Is Activated by DNA Stimulation}

To further investigate whether PKZ can be phosphorylated or not, CO cells were transfected with PKZ-FLAG. Twenty-four hours later, cells were separately transfected with $2 \mu \mathrm{g}$ of poly I:C, $2 \mu \mathrm{g}$ of poly (dA:dT), and $2 \mu \mathrm{g}$ of poly (dG:dC) for $12 \mathrm{~h}$. PKZ-FLAG protein was immunoprecipitated from cell lysates. The phosphorylation of PKZ-FLAG was detected with an antiphospho-Ser/Thr/Tyr antibody. These results show that poly (dA:dT) and poly (dG:dC) can promote PKZ phosphorylation but poly I:C cannot; and poly (dG:dC) had stronger effects on PKZ than poly (dA:dT) (Figure 4A). Poly (dG:dC) was therefore selected as a stimulator for PKZ-dependent pathway in subsequent experiments.

Subsequently, two sets of PKZ constructs containing FLAG tag and GFP tag were used in the co-IP assay. Co-IP assay was performed for HEK-293T cells. The plasmids of PKZFLAG and PKZ-GFP were co-transfected into HEK-293T cells. Twenty-four hours post-transfection, the cells were divided into two groups, namely the poly (dG:dC)-stimulated group and a non-stimulated group. In the poly ( $\mathrm{dG}: \mathrm{dC})$-stimulated group, anti-GFP antibody-immunoprecipitated protein complex was detected by anti-FLAG (PKZ-FLAG) antibody; which was however not detected in the non-stimulated group. Likewise, anti-FLAG antibody-immunoprecipitated protein complex was detected with the anti-GFP (PKZ-GFP) antibody in the poly (dG:dC) stimulated group. IgG-immunoprecipitated protein complex was not detected with anti-GFP (PKZ-GFP) or antiFLAG (PKZ-FLAG) antibody (Figure 4B). Co-IP results suggest that poly (dG:dC) promotes dimerization of PKZ. Overall, these findings demonstrate that fish PKZ can be activated by DNA stimulation.

\section{PKZ Initiates IFN Expression}

To confirm whether or not PKZ can trigger innate immunity, PKZ-pcDNA3.1 was over-expressed in both CIK cells (Figure 5A) and CO cells (Figure 5B). Twenty-four hours after transfection, cells were treated with equal amount of poly (dG:dC) for $6 \mathrm{~h}$. The promoter activity of grass carp IFN was increasingly upregulated in comparison with that of the cells transfected with basic-pcDNA3.1, and results indicated that IFN transcription level was upregulated in CIK or $\mathrm{CO}$ cells overexpressed PKZ. However, after knockdown of PKZ, the mRNA and protein levels of PKZ and IFN were significantly downregulated (Figures 5C,D). In addition, IFN transcription 
A
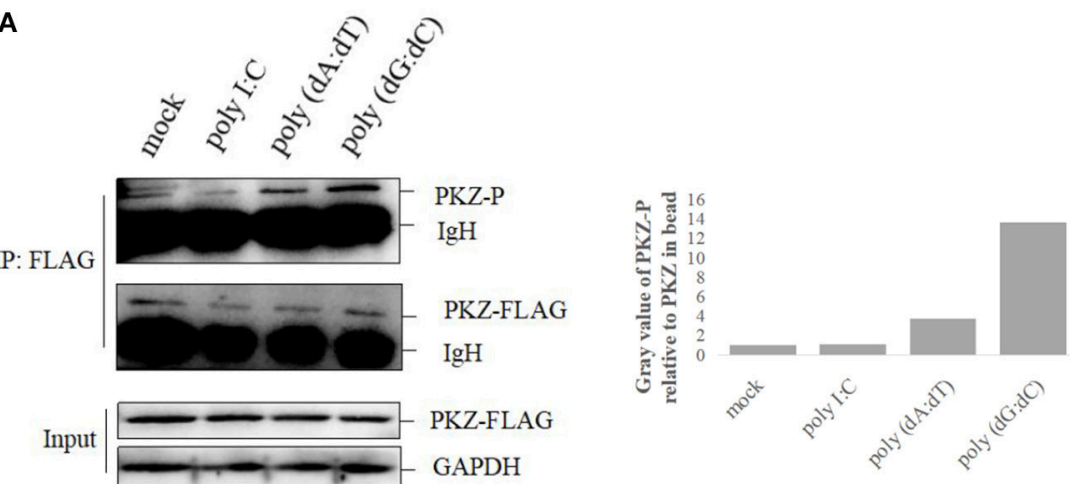

B

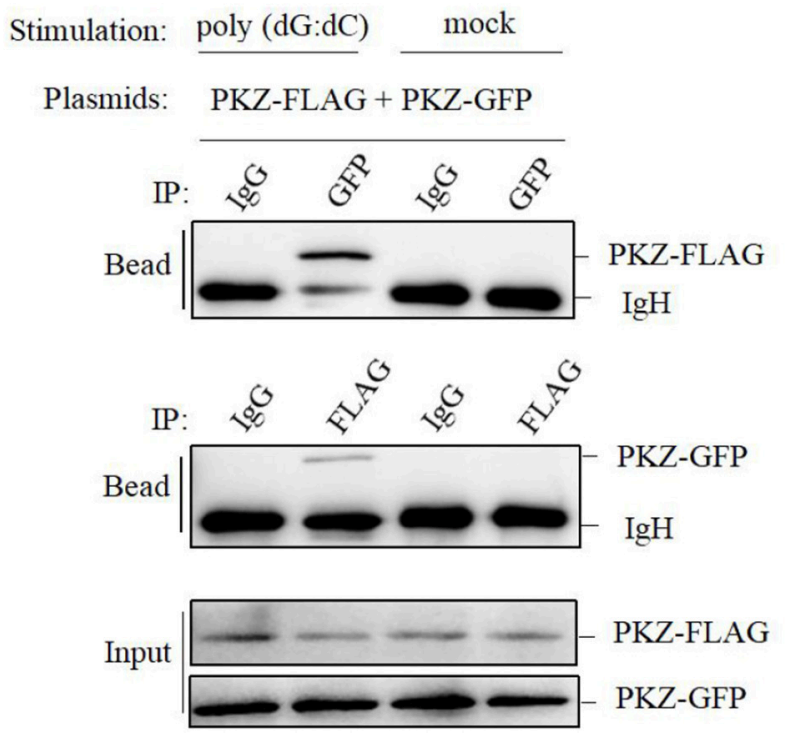

FIGURE 4 | PKZ is activated by DNA-stimulation. (A) CO cells seeded in $10 \mathrm{~cm}$ diameter dishes were transfected with $2 \mu \mathrm{g}$ PKZ-FLAG, $24 \mathrm{~h}$ later, negative control of cells was co-transfected with basic-pcDNA3.1, positive controls of cells were individually transfected with poly l:C, poly (dA:dT), poly (dG:dC), and experimental cells were co-transfected with PKZ-pcDNA3.1. After $12 \mathrm{~h}$, cell lysates were immunoprecipitated with anti-FLAG antibody, then the immunoprecipitants were examined by Western blotting with anti-phospho-Ser/Thr/Tyr antibody (AnaSpec, CA). (B) Co-IP assays were carried out in HEK-293T cells. The cells seeded in $10 \mathrm{~cm}$ diameter dishes were separately co-transfected with PKZ-FLAG and PKZ-GFP. This experiment was divided into two groups: one group was stimulated with poly (dG:dC), and the other was not. Forty eight hours later, cell lysates were separately immunoprecipitated with anti-FLAG antibody, anti-GFP antibody and lgG (used as a control), then the immunoprecipitants were examined by Western blotting. Each Western blot is representative of at least three independent experiments.

level was upregulated by transfection with PKZ in higher concentrations in CO cells (stimulated with poly (dG:dC) of equal strength for $6 \mathrm{~h}$ prior to experiments) (Figure 5E). The transfection efficiency was shown in Supplemental Figure 1. These results indicate that PKZ plays critical roles in inducing IFN under DNA stimulation.

In subsequent assays, the mutants were used to investigate the relationship between the PKZ structure and IFN expression. The mRNA and protein levels of IFN were upregulated in the overexpressed PKZ-C terminus and PKZ-wt. However, no evidence was found that the PKZ-N terminus and Ser ${ }^{198}$ PKZ deficit contributed to IFN expression (Figures 5F,G). These data suggest that PKZ can promote IFN expression by PKZ-C terminus.

\section{PKZ Interacts With Mediators of IRF3- and ISGF3-Like Dependent Pathway}

To further explore the mechanism of PKZ upregulating IFN expression, it is necessary to identify the PKZ-dependent pathway. A previous study has found that PKZ can interact with eIF2 $\alpha$ (31), so eIF2 $\alpha$ was chosen as a positive control in this experiment. Co-IP assays were performed with HEK293T cells, in which $P K Z$-FLAG were individually co-overexpressed with 


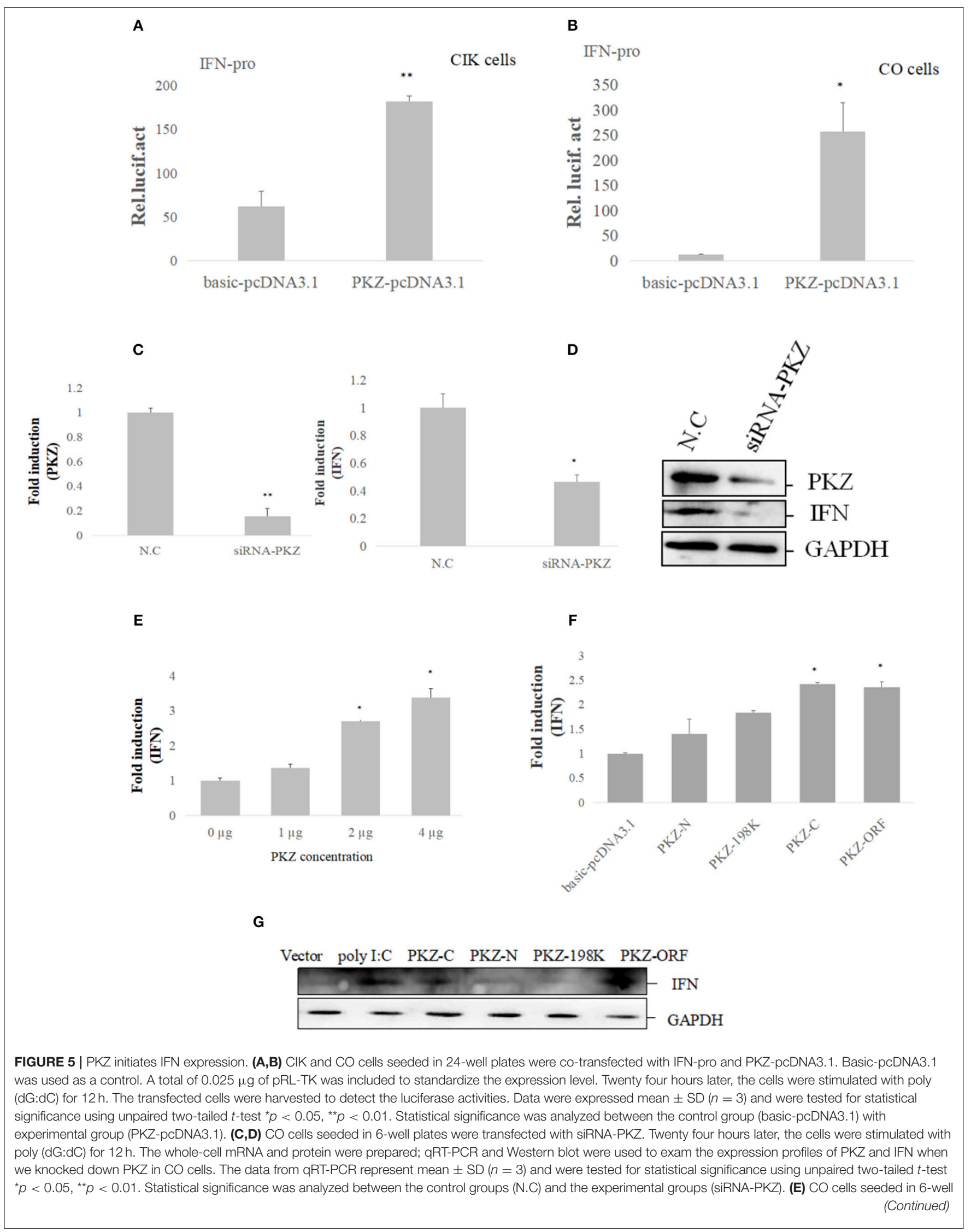


FIGURE 5 | plates were individually transfected with PKZ-pcDNA3.1 in concentrations of 0, 1, 2, and $4 \mu \mathrm{g}$, then qRT-PCR was used to detect the expression of IFN qRT-PCR represents mean $\pm S D(n=3)$ and was tested for statistical significance using unpaired two-tailed $t$-test ${ }^{*} p<0.05$. Fold changes were determined relative to cell transfected with $0 \mu \mathrm{g}$ of PKZ-pcDNA3.1. (F,G) CO cells seeded in 6-well plates were separately transfected with PKZ-pcDNA3.1, PKZ-C-pcDNA3.1, PKZ-N-pcDNA3.1, PKZ-198K-pcDNA3.1, and basic-pcDNA3.1. Twenty four hours later, the cells were stimulated with poly (dG:dC) for 12h. qRT-PCR and Western blot were used to exam the induction of IFN. The data from QRT-PCR represent mean \pm SD $(n=3)$ and were tested for statistical significance using unpaired two-tailed $t$-test ${ }^{*} p<0.05$. Statistical significance was analyzed between the control groups (basic-pcDNA3.1) and the experimental groups (PKZ-pcDNA3.1, PKZ-C-pcDNA3.1, PKZ-N-pcDNA3.1, PKZ-198K-pcDNA3.1). Each Western blot is representative of at least three independent experiments.

the following recombinant plasmids (IRF3-GFP, STING-GFP, ZDHHC1-GFP, IRF9-GFP, STAT1-GFP, STAT2-GFP, STAT6-GFP, and $e I F 2 \alpha$-GFP). Forty-eight hours post-transfection, the cells were stimulated with poly (dG:dC) for $6 \mathrm{~h}$ before all the proteins were harvested. IgG-immunoprecipitation acts as a negative control, anti-FLAG antibody-immunoprecipitation (Figure 6A) and anti-GFP antibody-immunoprecipitation (Figure 6B) show significant interaction between PKZ-FLAG and IRF3-GFP, STING-GFP, ZDHHC1-GFP, eIF2 $\alpha$-GFP, IRF9-GFP, and STAT2GFP. These results show that PKZ can interact with IRF3, STING, ZDHHC1, eIF2 $\alpha$, IRF9, and STAT2.

\section{PKZ Initiates IFN Expression Through IRF3- and ISGF3-Like Dependent Pathways}

Subsequent experiments were conducted to determine the relationships among PKZ and some common mediators of innate immunity. Dimerization and phosphorylation levels of IRF3 were increased when $\mathrm{CO}$ cells were transfected with poly I:C, poly (dA:dT), poly (dG:dC) and PKZ-pcDNA3.1, with pcDNA3.1basic acting as negative control (Figure 7A). Interestingly, STAT2 phosphorylation activity was also enhanced in the process (Figure 7B). Moreover, IFN expression was upregulated in CO cells in which IRF3, STING, ZDHHC1, IRF9, and STAT2 were overexpressed. However, the knockdown of PKZ blocked the IFN expression (Figures 7C-E), whereas knockdown of IRF3 or IRF9 inhibited the IFN expression through PKZ (Figures 7F,G). The effect of siRNA-IRF9 was examined in Supplemental Figure 2. These data suggest that PKZ initiated immune responses through mediators of the IRF3 dependent pathway (IRF3, STING, and ZDHHC1) as well as the ISGF3-like (IRF9 and STAT2) dependent pathway (Figure 8).

\section{DISCUSSION}

In mammals, eIF $2 \alpha$ is phosphorylated with one of the eIF $2 \alpha$ kinases that consist of PKR, PKR-like ER kinase (PERK), general control non-derepressible-2 (GCN2), and hemeregulated eIF2 $\alpha$ kinase (HRI) (38). Among these kinases, PKR is most widely studied. PKR is known to mediate IKBkinase $\beta$ (IKK $\beta)$ phosphorylation and be able to activate the NF-KB pathway (39). PKR also inhibits viral protein synthesis via eIF2 $\alpha$ phosphorylation (40) and thus helps resist virus infection $(41,42)$. Because the fish-specific protein kinase PKZ is homologous with mammalian PKR, it was believed-for a short while-that it is a duplicate of mammalian PKR (28-30). That PKZ possesses some functions similar to those of $\operatorname{PKR}(31,33,43-45)$ is not in question.
Fish PKZ have been identified in C. idellus, Carassius auratus, Atlantic salmon, Gobiocypris rarus, and Danio rerio (28-30, 32, 44). BLAST homologous research indicates that C. idellus PKZ full-length cDNA has 2,158 bp with a largest open reading frame (ORF) encoding 513 amino acid and shares high-level homology with other fish PKZ (32). All fish PKZ contain two Z $\alpha$ domain in $\mathrm{N}$-terminus and a conserved catalytic domain in C-terminus (28-30, 32, 44).

Ctenopharyngodon idellus PKZ induces the apoptosis through eIF2 $\alpha$ phosphorylation (33). In the same way dsRNA induction lead to PKR auto-phosphorylation and auto-dimerization (4648), PKZ can interact with the [poly (dA:dT) DNA or poly (dG:dC)], though it cannot interact with dsRNA (Figure 3), just as poly (dA:dT) and poly (dG:dC) can facilitate PKZ phosphorylation but poly I:C cannot (Figure 4A). Because of this, poly (dG:dC) was chosen as activator for PKZ in our subsequent study. Besides PKZ phosphorylation, poly (dG:dC) promotes PKZ dimerization (Figure 4B). Consistently with our results, the N-terminus of crucian carp PKZ was found not to interact with poly I:C and this indicates that dsRNA is unable to activate PKZ (31). It was also observed that PKZ is located in the cytoplasm (Figure 2), where the binding with infected DNA takes place. We believe strongly that PKZ may act as an essential cellular DNA receptor.

It is well-known that DNA sensors can promote IFN- $\beta$ expression, and PKZ facilitates type I IFN expression in different grass carp cell lines, which indicates how so that PKZ has identical functions in various types of fish cells (Figures 5A-D). As indicated, IFN expression was gradually upregulated with increasing concentrations of overexpressed PKZ in the experiments (Figure 5E), and there is clear evidence of functional differentiation in the kinase domain and $\mathrm{Z} \alpha$ domain of PKZ. The N-terminal $\mathrm{Z} \alpha$ domain is mainly responsible for recognizing cytoplasmic DNA and also has B-Z transition activity $(49,50)$. The C-terminal kinase catalytic domain of PKZ plays a significant role in triggering IFN expression (Figures 5F,G). A similar observation was also documented in cGAS (16). Liu et al. (31) have also suggested that fish PKZ is a new cytosolic sensor for DNA detection by virtue of the unique $\mathrm{N}$-terminal $\mathrm{Z} \alpha$ domains.

DNA-sensed PRRs used to make intrinsic immunestimulating properties of plasmid DNA vaccines can recognize intracellular DNA (51). For example, DAI can be used to make intrinsic immune-stimulating property of plasmid DNA vaccines which promote the transcription of genes encoding type I IFNs, proinflammatory cytokines, and co-stimulatory molecules (52). Our findings may provide a potential applicability for DNA vaccines. This is to say that PKZ also could be used to make 


\section{A}

\section{PKZ-FLAG}

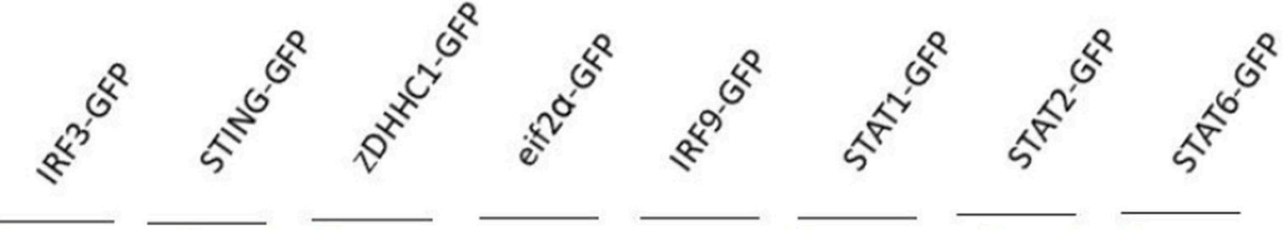

IP: Flag IgG Flag IgG Flag IgG Flag IgG Flag IgG Flag IgG Flag IgG Flag IgG

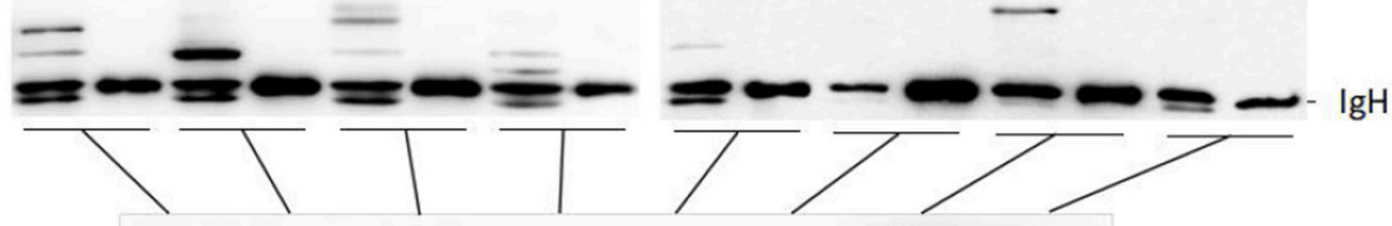

Lysate

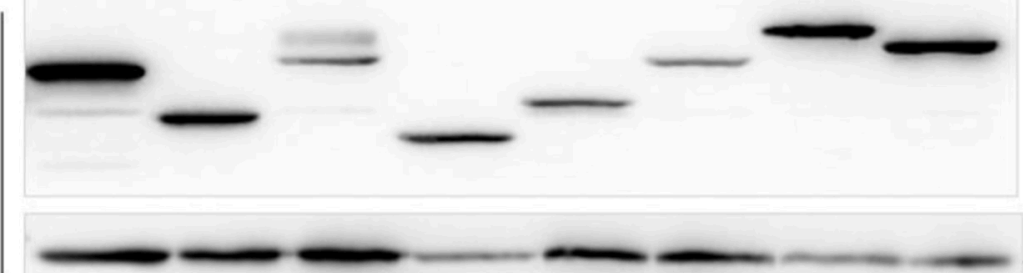

PKZ-FLAG

B

\section{PKZ-FLAG}

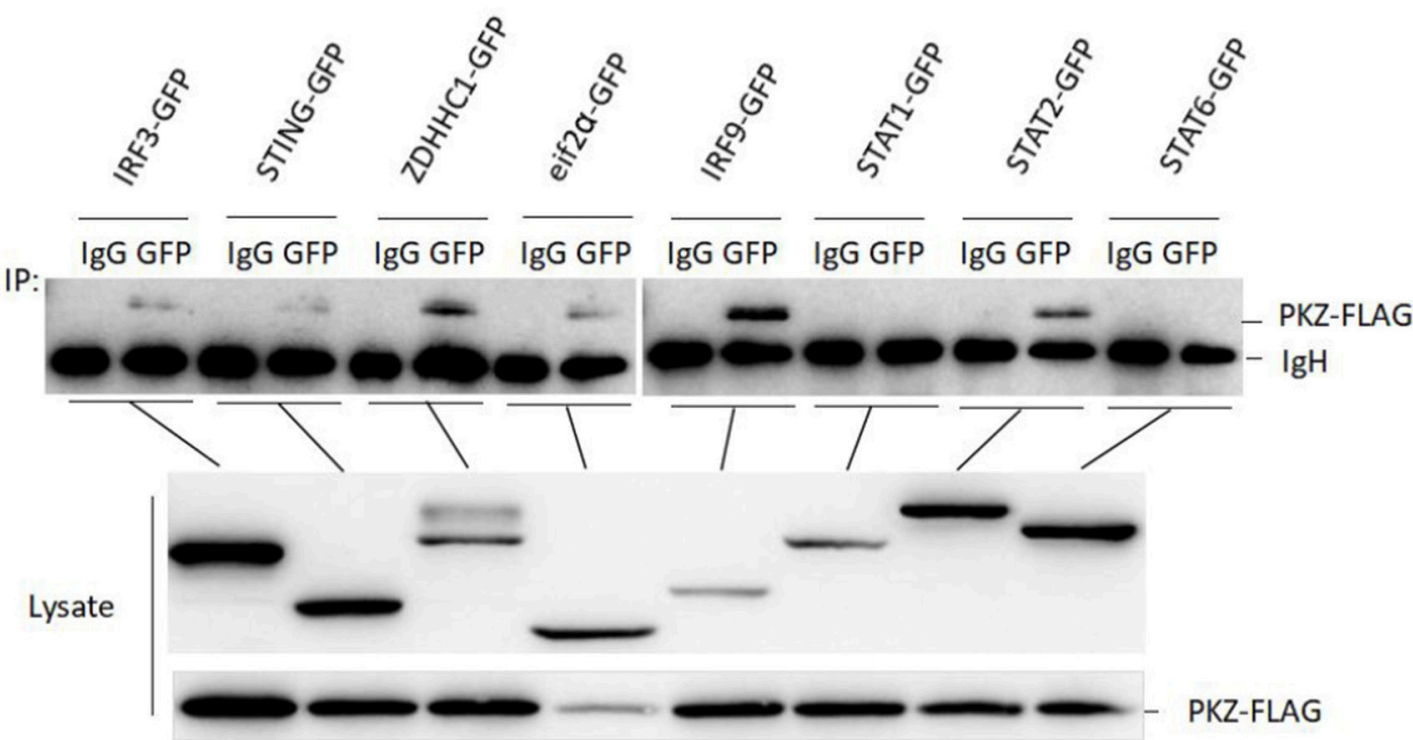

FIGURE 6 | PKZ interacts with the mediators of IRF3-dependent and ISGF3-like dependent pathways. (A,B) HEK-293T cells seeded in $10 \mathrm{~cm}$ diameter dishes were separately co-transfected PKZ-FLAG with one of the following recombinant plasmids (IRF3-GFP, STING-GFP, ZDHHC1-GFP, elF2 $\alpha$-GFP, IRF9-GFP, STAT1-GFP, STAT2-GFP, and STAT6-GFP), this experiment was divided into two groups: one group was immunoprecipitated with anti-FLAG antibody and the other group was immunoprecipitated with anti-GFP antibody. Forty eight hours later, cell lysates were separately immunoprecipitated with anti-FLAG (anti-GFP) antibody and lgG. Then the immunoprecipitants were examined by Western blot with the anti-GFP (anti-FLAG) antibody. The molecular masses of IRF3-GFP, STING-GFP, ZDHHC1-GFP, elF2 $\alpha$-GFP, IRF9-GFP, STAT1-GFP, STAT2-GFP, and STAT6-GFP are 85, 70, 85, 60, 80, 90, 98, and 87 kD, respectively. Each Western blot is representative of at least three independent experiments. 
DNA vaccines. Meanwhile, $\mathrm{PKZ}$ provides mediated basics for poly (dA:dT) and poly (dG:dC) acting as immune inducers in up-regulation of IFN. We believe that PKZ could be used to make DNA vaccines and our findings may be a useful contribution in that regard.

Though PKZ is known to be able to initiate IFN expression, the PKZ-mediated pathways need further study, which was done in our subsequent experiments. The IFN-induction pathway mainly includes IRF3-dependent and ISGF3-dependent pathways $(53,54)$. The IRF3-dependent pathway is primarily responsible for IFN and ISGs expression at the early stages of viral infection (55), while the ISGF3-dependent pathway is responsible at the later period of infection (56). It is well-known that IRF3 (35), STING (21), and ZDHHC1 (57) are the members

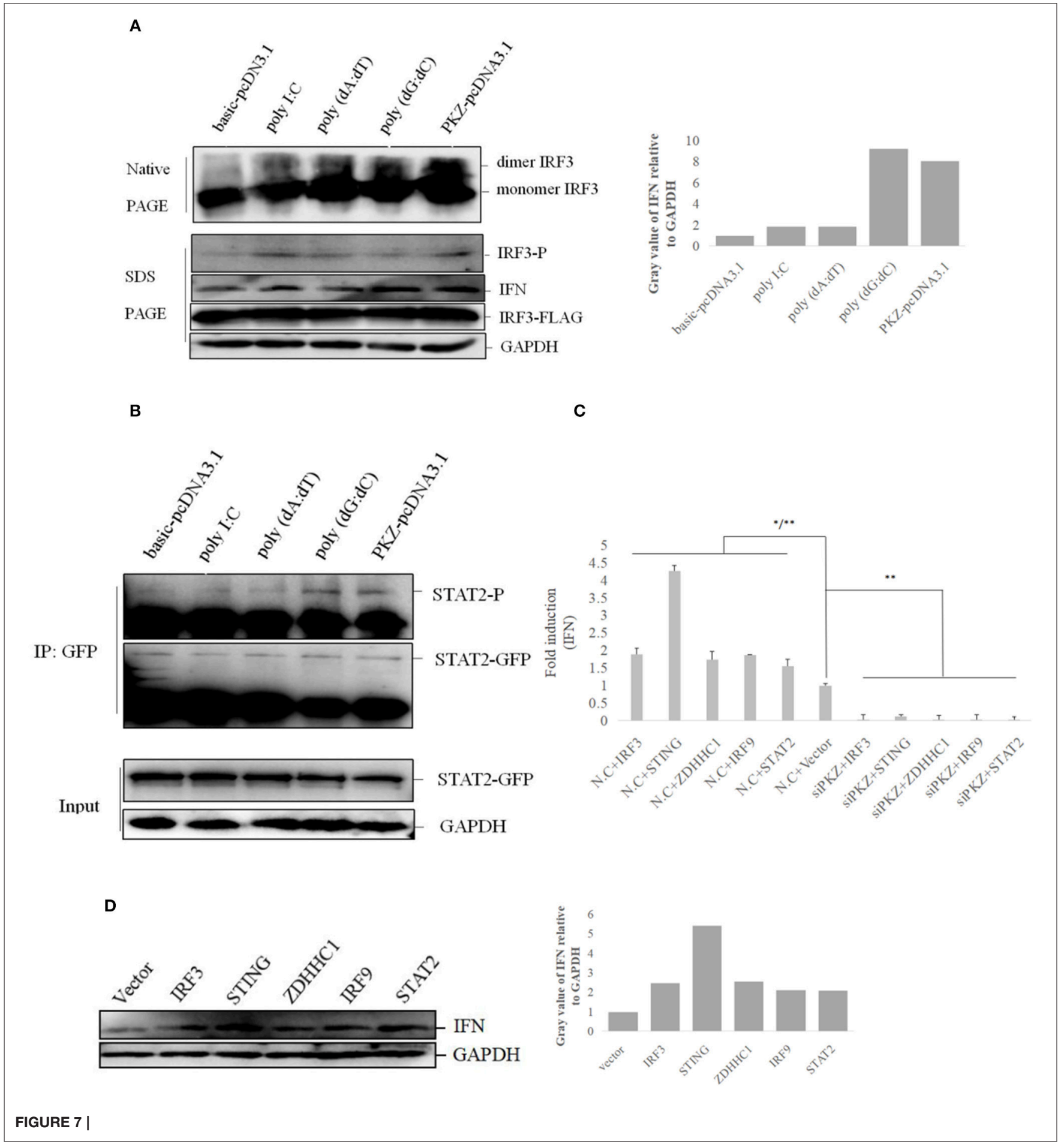




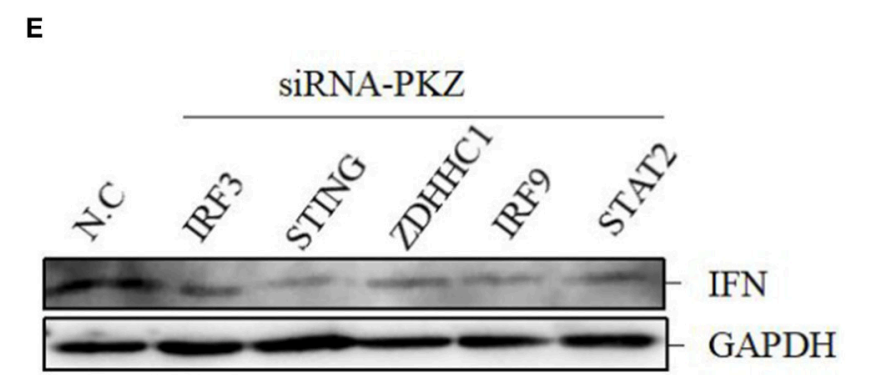

F

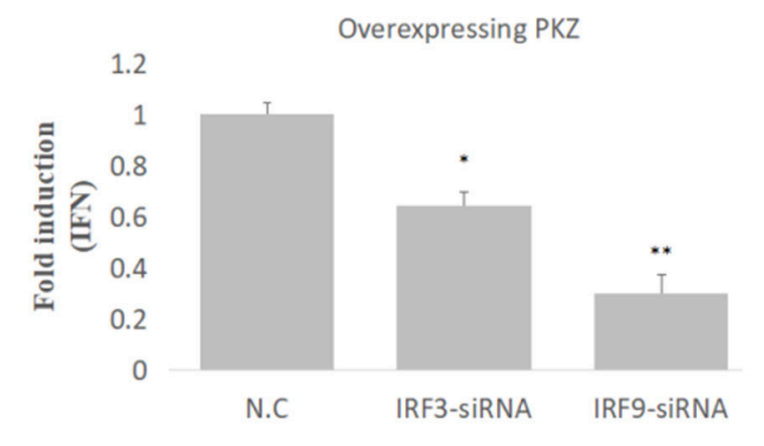

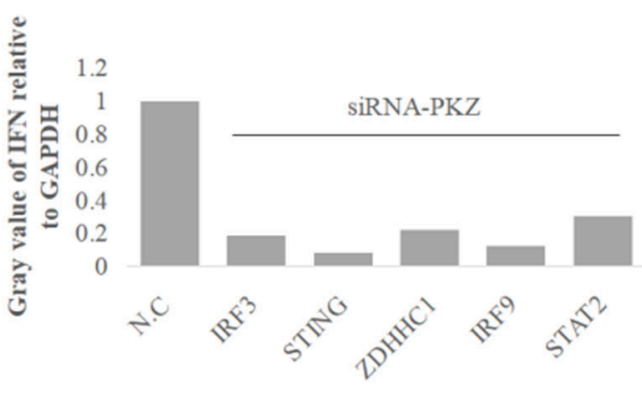

G
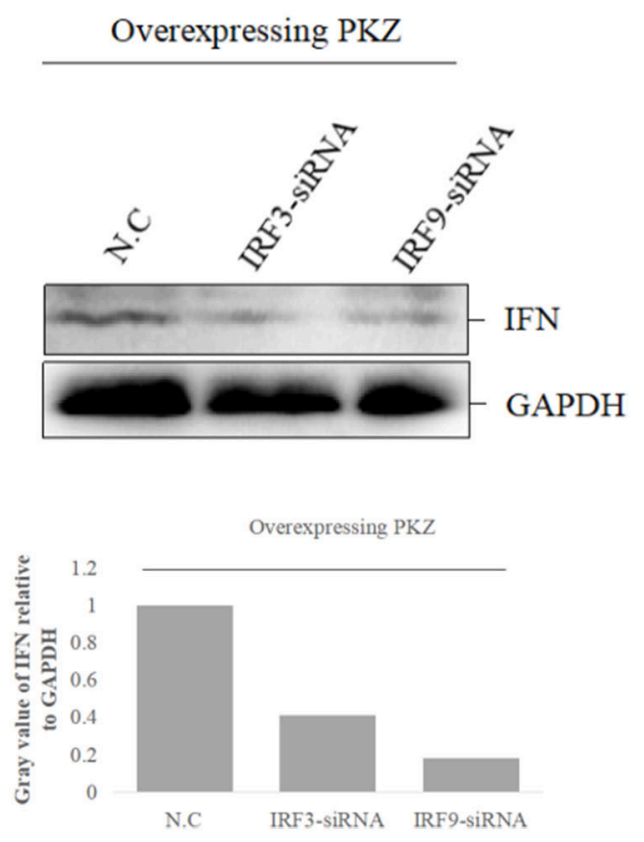

FIGURE 7 | PKZ initiates IFN expression via IRF3-dependent and ISGF3-like-dependent pathways. (A) CO cells seeded in $10 \mathrm{~cm}$ diameter dishes were separately transfected with the negative control (basic-pcDNA3.1), the positive control [poly I:C, poly (dA:dT), poly (dG:dC)] and the experimental group (PKZ-pcDNA3.1) plasmids. Twenty four hours after transfection, the transfected cells were harvested for SDS-PAGE or native PAGE and immunoblotting with the indicated antibodies. (B) CO cells seeded in $10 \mathrm{~cm}$ diameter dishes were transfected with STAT2-GFP. Twenty four hours after transfection, the cells were separately transfected with the negative control (basic-pcDNA3.1), the positive controls [poly I:C, poly (dA:dT), poly (dG:dC)], and the experimental group (PKZ-pcDNA3.1) plasmids for 12 h. The cell lysates were immunoprecipitated with anti-GFP antibody, the immunoprecipitants were examined by Western blot with anti-phospho-Ser/Thr/Tyr antibody (AnaSpec, CA). (C-E) CO cells seeded in 24-well plates were transfected with siRNA-PKZ or N.C. Twenty four hours after transfection, the cells were separately transfected with IRF3-pcDNA3.1, STING-pcDNA3.1, ZDHHC1-pcDNA3.1, IRF9-pcDNA3.1, STAT2-pcDNA3.1, and basic-pcDNA3.1 in siRNA-PKZ groups and N.C. groups. The cells were harvested to carry out qRT-PCR and Western blotting. The data from qRT-PCR represent mean \pm SD $(n=3)$ and were tested for statistical significance using unpaired two-tailed $t$-test ${ }^{*} p<0.05,{ }^{* \star} p<0.01$. The asterisk above the error bars indicated statistical significance using the group co-transfected with basic-pcDNA3.1 and N.C. The asterisk above the bracket indicated statistical significance between the groups transfected N.C and the groups transfected with PKZ-siRNA (F,G). The whole-cell mRNA or protein were prepared, qRT-PCR and Western blot were used to exam the expression of IFN when we knocked down IRF3 or IRF9 in CO cells. Endogenous GAPDH was detected as a loading control. The data from qRT-PCR represent mean \pm SD $(n=3)$ and were tested for statistical significance using unpaired two-tailed $t$-test. Asterisks indicate significant differences from control (N.C) ${ }^{*} p<0.05$, ${ }^{* \star} p<0.01$. Fold changes were determined relative to cell transfected with N.C. Each Western blot is representative of at least three independent experiments.

of the IRF3-dependent pathway. Our previous results show that grass carp IRF3, STING, and ZDHHC1 are all upregulated under stimulation with poly (dA:dT) and poly (dG:dC) (35). The expression characteristic of PKZ is similar to those of IRF3, STING, and ZDHHC1 under stimulations with different DNAs (Figure 1). In addition, PKZ can directly interact with these mediators under stimulation by poly (dG:dC) (Figure 6).
ISGF3 (IRF9/STAT1/STAT2) acts as a transcription regulator induced by IFN (58). However, many studies have shown that STAT2 rather than STAT1 is the catalytic domain for ISGF3 $(59,60)$. Therefore, IRF9 and STAT2 are the major subunits of the ISGF3 complex. This functional unit is known as ISGF3like. Our previous studies also found that grass carp IRF9 and STAT2 can form an activated heterodimer (61). In this paper, 


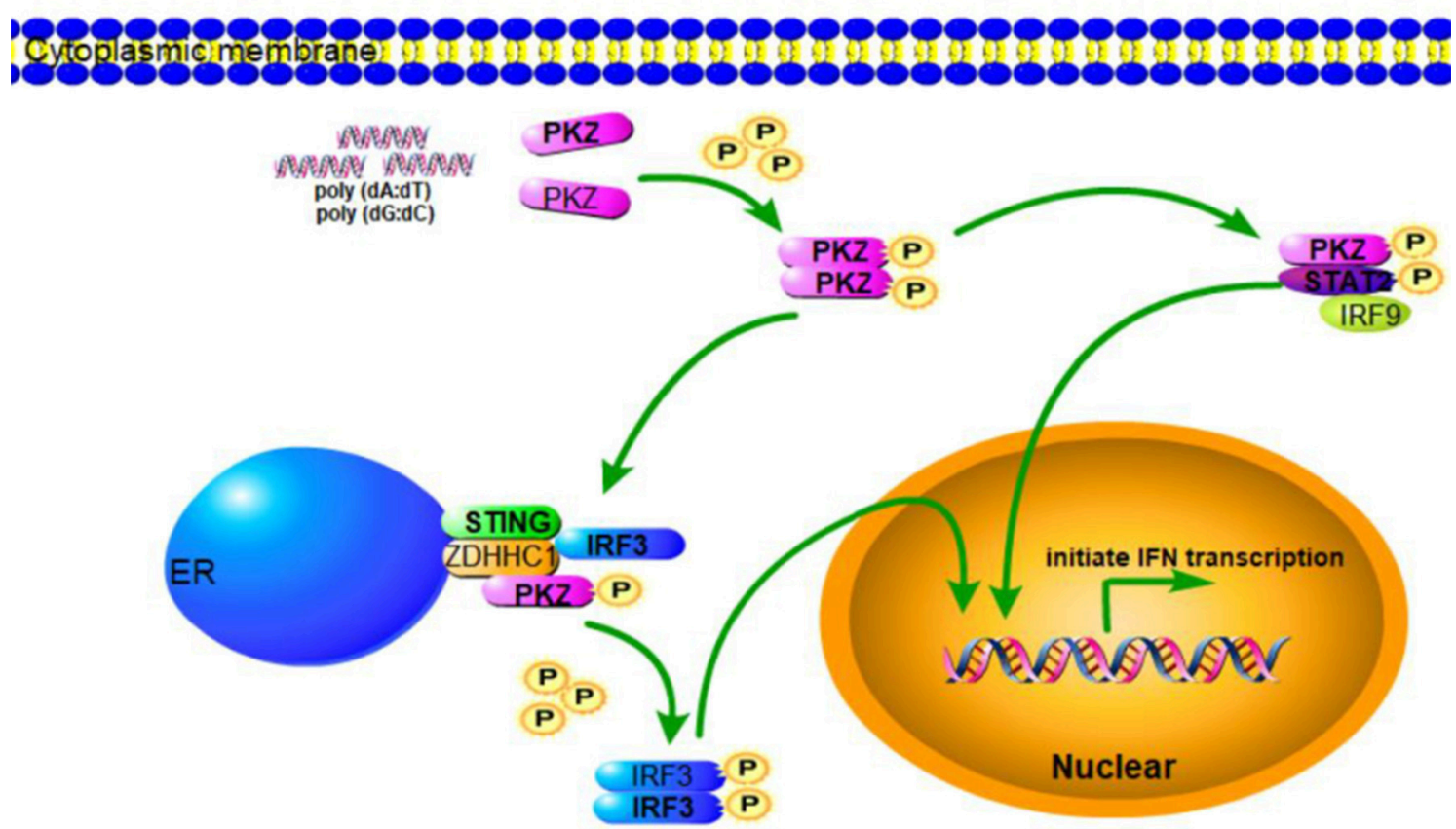

FIGURE 8 | Schematic representation of PKZ-mediated signaling pathway. In response to DNA infection, PKZ-mediated IFN signaling pathway is activated. PKZ interacts with the mediators of IRF3-dependent and ISGF3-like dependent signaling pathways and phosphorylates IRF3 and STAT2, and thus helps induce immune responses.

we have shown that PKZ can interact directly with ISGF3-like under stimulation with poly (dG:dC) (Figure 6). We believe it likely that PKZ triggers antiviral activity in an ISGF3-like dependent pathway.

PKZ was shown to promote the IRF3 dimerization and phosphorylation (Figure 7A) and increase STAT2 phosphorylation (Figure 7B). These results indicate that PKZ can respond to DNA stimulation and activate IRF3 and ISGF3-like. IFN expression is activated in IRF3- and ISGF3-likemediated pathways, which are dependent on the presence of PKZ (Figures 7C-E).

In conclusion, when cells are invaded by pathogenic DNA, PKZ recognizes it and then binds with it. The activated PKZ first interacts with and activates the mediators of the IRF3-dependent pathway to form the tetramer of PKZ-IRF3STING-ZDHHC1, and then activates IRF3. In the ISGF3like mediated pathway, the activated PKZ can activate the dimer of IRF9-STAT2 to form the trimer of PKZ-IRF9-STAT2 (Figure 8). Notably, these data indicate that fish PKZ gives antiviral signals in IRF3-dependent or ISGF3-like dependent pathways under stimulation with DNA, and thus helps initiate immune responses.

\section{AUTHOR CONTRIBUTIONS}

$\mathrm{CH}$ supervised the research. XX conceived the study, designed, and performed the experiments and wrote the manuscript. ML, XX, DL, BC, HM, and CW analyzed the experiments and data. ZJ, and CL provided reagents, technical assistance and contributed to completion of the study. DL revised the manuscript. All authors reviewed the results and approved the final version of the manuscript.

\section{FUNDING}

This work was supported by Major projects of Natural Science Foundation of Jiangxi Province (20171ACB20004), the National Natural Science Foundation of China (Grant 31472304), the earmarked fund for Jiangxi Agriculture Research System (Grant JXARS-04), the Graduate Innovation Special Fund of Nanchang University (Grant CX2016200), the Science and Technology Project of Education Department of Jiangxi Province (GJJ180112), Science and Technology Innovation Special Fund of National Science and Technology Department (2018ZDF40023), and the Science \& Technology Foundations of Education Department of Jiangxi (GJJ161303).

\section{ACKNOWLEDGMENTS}

We are gratitude to Prof. Pin Nie (Institute of Hydrobiology, Chinese Academy of Sciences, Wuhan, China) for providing us with CO cells.

\section{SUPPLEMENTARY MATERIAL}

The Supplementary Material for this article can be found online at: https://www.frontiersin.org/articles/10.3389/fimmu. 2019.00582/full\#supplementary-material 


\section{REFERENCES}

1. Chen SN, Zou PF, Nie P. Retinoic acid-inducible gene I (RIG-I)-like receptors (RLRs) in fish: current knowledge and future perspectives. Immunology. (2017) 151:16-25. doi: 10.1111/imm.12714

2. Zhang YB, Gui JF. Molecular regulation of interferon antiviral response in fish. Dev. Comp. Immunol. (2012) 38:193-202. doi: 10.1016/j.dci.2012.06.003

3. Paludan SR, Bowie AG. Immune sensing of DNA. Immunity. (2013) 38:87080. doi: 10.1016/j.immuni.2013.05.004

4. Wilkins C, Gale M Jr. Recognition of viruses by cytoplasmic sensors. Curr Opin Immunol. (2010) 22:41-7. doi: 10.1016/j.coi.2009.12.003

5. Seth RB, Sun L, Chen ZJ. Antiviral innate immunity pathways. Cell Res. (2006) 16:141-7. doi: 10.1038/sj.cr.7310019

6. Akira S, Hemmi H. Recognition of pathogen-associated molecular patterns by TLR family. Immunol Lett. (2003) 85:85-95. doi: 10.1016/S0165-2478(02)00228-6

7. Akira S, Uematsu S, Takeuchi O. Pathogen recognition and innate immunity. Cell. (2006) 124:783-801. doi: 10.1016/j.cell.2006.02.015

8. Alexopoulou L, Holt AC, Medzhitov R, Flavell RA. Recognition of doublestranded RNA and activation of NF-kB by Toll-like receptor 3. Nature. (2001) 413:732-8. doi: 10.1016/j.cell.2006.02.015

9. O'neil LAJ, Bowie AG. The family of five: TIR-domain-containing adaptors in Toll-like receptor signalling. Nat Rev Immunol. (2007) 7:353-64. doi: 10.1038/nri2079

10. Pichlmair A, Sousa CR. Innate recognition of viruses. Immunity. (2007) 27:370-83. doi: 10.1016/j.immuni.2007.08.012

11. Bürckstümmer $\mathrm{T}$, Baumann $\mathrm{C}$, Blüml S, Dixit E, Dürnberger G, Jahn $\mathrm{H}$, et al. An orthogonal proteomic-genomic screen identifies AIM-2 as a cytoplasmic DNA sensor for the inflammasome. Nat Immunol. (2009) 10:26672. doi: 10.1038/ni.1702

12. Takaoka A, Wang Z, Choi MK, Yanai H, Negishi H, Ban T, et al. DAI (DLM-1/ZBP1) is a cytosolic DNA sensor and an activator of innate immune response. Nature. (2007) 448:501-6. doi: 10.1038/nature06013

13. Unterholzner L, Keating SE, Baran M, Horan KA, Jensen SB, Sharma S, et al. IFI16 is an innate immune sensor for intracellular DNA. Nat Immunol. (2010) 11:997-1004. doi: 10.1038/ni.1932

14. Zhang Z, Yuan B, Bao M, Lu N, Kim T, Liu YJ. The helicase DDX41 senses intracellular DNA mediated by the adaptor STING in dendritic cells. Nat Immunol. (2011) 12:959-65. doi: 10.1038/ni.2091

15. Chiu YH, Macmillan JB, Chen ZJ. RNA polymerase III detects cytosolic DNA and induces type I interferons through the RIG-I pathway. Cell. (2009) 138:576-91. doi: 10.1016/j.cell.2009.06.015

16. Sun L, Wu J, Du F, Chen X, Chen ZJ. Cyclic GMP-AMP synthase is a cytosolic DNA sensor that activates the type I interferon pathway. Science. (2013) 339:786-91. doi: 10.1126/science. 1232458

17. Abe T, Harashima A, Xia T, Konno H, Konno K, Morales A, et al. STING recognition of cytoplasmic DNA instigates cellular defense. Mol Cell. (2013) 50:5-15. doi: 10.1016/j.molcel.2013.01.039

18. Ishikawa H, Barber GN. STING is an endoplasmic reticulum adaptor that facilitates innate immune signalling. Nature. (2008) 455:674-8. doi: $10.1038 /$ nature 07317

19. Ouyang S, Song X, Wang Y, Ru H, Shaw N, Jiang Y, et al. Structural analysis of the STING adaptor protein reveals a hydrophobic dimer interface and mode of cyclic di-GMP Binding. Immunity. (2012) 36:1037-86. doi: 10.1016/j.immuni.2012.03.019

20. Shu C, Yi G, Watts T, Kao CC, Li P. Structure of STING bound to cyclic di-GMP reveals the mechanism of cyclic dinucleotide recognition by the immune system. Nat Struct Mol Biol. (2012) 19:722-4. doi: 10.1038/nsmb .2331

21. Zhong B, Yang Y, Li S, Wang YY, Li Y, Diao F. The Adaptor protein MITA links virus-sensing receptors to IRF3 transcription factor activation. Immunity. (2008) 29:538-50. doi: 10.1016/j.immuni.2008.09.003

22. Zou PF, Chang MX, Li Y, Huan Zhang S, Fu JP, Chen SN, et al. Higher antiviral response of RIG-I through enhancing RIG-I/MAVS-mediated signaling by its long insertion variant in zebrafish. Fish Shellfish Immunol. (2015) 43:13-24. doi: $10.1016 /$ j.fsi.2014.12.001
23. Zou PF, Chang MX, Xue NN, Liu XQ, Li JH, Fu JP, et al. Melanoma differentiation-associated gene 5 in zebrafish provoking higher interferonpromoter activity through signalling enhancing of its shorter splicing variant. Immunol. (2014) 141:192-202. doi: 10.1111/imm.12179

24. Chang M, Collet B, Nie P, Lester K, Campbell S, Secombes CJ, et al. Expression and functional characterization of the RIG-I-like receptors MDA5 and LGP2 in rainbow trout (Oncorhynchus mykiss). J Virol. (2011) 85:8403-12. doi: 10.1128/JVI.00445-10

25. Ohtani M, Hikima J, Kondo H, Hirono I, Jung TS, Aoki T. Characterization and antiviral function of a cytosolic sensor gene, MDA5, in Japanese flounder, Paralichthys olivaceus. Dev Comp Immunol. (2011) 35:554-62. doi: 10.1016/j.dci.2010.12.013

26. Ohtani M, Hikima J, Kondo H, Hirono I, Jung TS, Aoki T. Evolutional conservation of molecular structure and antiviral function of a viral RNA receptor, LGP2, in Japanese flounder, Paralichthys olivaceus. J Immunol. (2010) 185:7507-17. doi: 10.4049/jimmunol. 1001850

27. Palti Y. Toll-like receptors in bony fish: from genomics to function. Dev Comp Immunol. (2011) 35:1263-72. doi: 10.1016/j.dci.2011.03.006

28. Bergan V, Jagus R, Lauksund S, Kileng $\varnothing$, Robertsen B. The Atlantic salmon Z-DNA binding protein kinase phosphorylates translation initiation factor 2 alpha and constitutes a unique orthologue to the mammalian dsRNA-activated protein kinase R. FEBS J. (2008) 275:184-97. doi: 10.1111/j.1742-4658.2007.06188.x

29. Hu CY, Zhang YB, Huang GP, Zhang QY, Gui JF. Molecular cloning and characterisation of a fish PKR-like gene from cultured CAB cells induced by UV-inactivated virus. Fish Shellfish Immunol. (2004) 17:353-66. doi: 10.1016/j.fsi.2004.04.009

30. Rothenburg S, Deigendesch N, Dittmar K, Koch-Nolte F, Haag F, Lowenhaupt $\mathrm{K}$, et al. A PKR-like eukaryotic initiation factor $2 \alpha$ kinase from zebrafish contains Z-DNA binding domains instead of dsRNA binding domains. Proc Natl Acad Sci USA. (2005) 102:1602-7. doi: 10.1073/pnas.0408 714102

31. Liu TK, Zhang YB, Liu Y, Sun F, Gui JF. Cooperative roles of fish protein kinase containing Z-DNA binding domains and double-stranded RNA-Dependent protein kinase in interferon-mediated antiviral response. J Virol. (2011) 85:12769-80. doi: 10.1128/JVI.05849-11

32. Yang PJ, Wu CX, Li W, Fan LH, Lin G, Hu CY. Cloning and functional analysis of PKZ (PKR-like) from grass carp (Ctenopharyngodon idellus). Fish Shellfish Immunol. (2011) 31:1173-8. doi: 10.1016/j.fsi.2011.10.012

33. Wu C, Hu Y, Fan L, Wang H, Sun Z, Deng S, et al. Ctenopharyngodon idella PKZ facilitates cell apoptosis through phosphorylating eIF2 $\alpha$. Mol Immunol. (2016) 69:13-23. doi: 10.1016/j.molimm.2015.11.006

34. White TE, Brandariz-Nuñez A, Martinez-Lopez A, Knowlton C, Lenzi G, Kim B, et al. A SAMHD1 mutation associated with Aicardi-Goutières Syndrome uncouples the ability of SAMHD1 to restrict HIV-1 from its ability to downmodulate type I interferon in humans. Hum Mutat. (2017) 38:658-68. doi: 10.1002/humu.23201

35. Xu X, Li M, Wu Z, Wang H, Wang L, Huang K, et al. Endoplasmic reticulum transmembrane proteins ZDHHC1 and STING both act as direct adaptors for IRF3 activation in teleost. J Immunol. (2017) 199:3623-33. doi: 10.4049/jimmunol.1700750

36. Zhang T, Li D, Wan L, Chen X, Wang X, Zhong B, et al. Ctenopharyngodon idella PERK (eIF2ak3) decreases cell viability by phosphorylating eIF2 $\alpha$ under ER stress. Fish Shellfish Immunol. (2017) 70:568-74. doi: 10.1016/j.fsi.2017.09.044

37. Zhong B, Mao H, Fan Q, Liu Y, Hu Y, Mi Y, et al. SiRNA-mediated knockdown of CiGRP78 gene expression leads cell susceptibility to heavy metal cytotoxicity. Gene. (2014) 552:219-24. doi: 10.1016/j.gene.2014.09.036

38. Wek RC, Jiang HY, Anthony TG. Coping with stress: eIF2 kinases and translational control. Biochem Soc Trans. (2006) 34(Pt 1):7-11. doi: 10.1042/BST20060007

39. Bonnet MC, Daurat C, Ottone C, Meurs EF. The N-terminus of PKR is responsible for the activation of the NF-kappaB signaling pathway by interacting with the IKK complex. Cell Signal. (2006) 18:1865-75. doi: 10.1016/j.cellsig.2006.02.010 
40. Dey M, Cao C, Dar AC, Tamura T, Ozato K, Sicheri F, et al. Mechanistic link between PKR dimerization, autophosphorylation, and eIF2alpha substrate recognition. Cell. (2005) 122:901-13. doi: 10.1016/j.cell.2005.06.041

41. Rojas M, Arias CF, López S. Protein kinase R is responsible for the phosphorylation of eIF2alpha in rotavirus infection. J Virol. (2010) 84:1045766. doi: 10.1128/JVI.00625-10

42. Lee SB, Esteban M. The interferon-induced double-stranded RNA-activated human p68 protein kinase inhibits the replication of vaccinia virus. Virology. (1993) 193:1037-41. doi: 10.1006/viro.1993.1223

43. Rothenburg S, Deigendesch N, Dey M, Dever TE, Tazi L. Double-stranded RNA-activated protein kinase PKR of fishes and amphibians: varying the number of double-stranded RNA binding domains and lineage-specific duplications. BMC Biol. (2008) 6:1-19. doi: 10.1186/1741-7007-6-12

44. Su J, Zhu Z, Wang Y. Molecular cloning, characterization and expression analysis of the PKZ gene in rare minnow Gobiocypris rarus. Fish Shellfish Immunol. (2008) 25:106-13. doi: 10.1016/j.fsi.2008.03.006

45. Liu ZY, Jia KT, Li C, Weng SP, Guo CJ, He JG. A truncated Danio rerio, PKZ isoform functionally interacts with eIF $2 \alpha$ and inhibits protein synthesis. Gene. (2013) 527:292-300. doi: 10.1016/j.gene.2013.05.043

46. McCormack SJ, Ortega LG, Doohan JP, Samuel CE. Mechanism of interferon action motif I of the interferon-induced, RNA-dependent protein kinase (PKR) is sufficient to mediate RNA-binding activity. Virol. (1994) 198:92-9. doi: 10.1006/viro.1994.1011

47. McKenna SA, Lindhout DA, Kim I, Liu CW, Gelev VM, Wagner G, et al. Molecular framework for the activation of RNA-dependent protein kinase. $J$ Biol Chem. (2007) 282:11474-86. doi: 10.1074/jbc.M700301200

48. Thomis DC, Samuel CE. Mechanism of interferon action: autoregulation of RNA-dependent p1/eIF-2 alpha protein kinase (PKR) expression in transfected mammalian cells. Proc Natl Acad Sci USA. (1992) 89:10837-41.

49. Kim D, Hur J, Park K, Bae S, Shin D, Ha SC, et al. Distinct Z-DNA binding mode of a PKR-like protein kinase containing a Z-DNA binding domain (PKZ). Nucleic Acids Res. (2014) 42:5937-48. doi: 10.1093/nar/gku189

50. Subramani VK, Kim D, Yun K, Kim KK. Structural and functional studies of a large winged Z-DNA-binding domain of Danio rerio protein kinase PKZ. FEBS Lett. (2016) 590:2275-85. doi: 10.1002/1873-3468.12238

51. DeFilippis VR, Alvarado D, Sali T, Rothenburg S, Fruh K. Human cytomegalovirus induces the interferon response via the DNA sensor ZBP1. J Virol. (2010) 84:585-98. doi: 10.1128/JVI.01748-09

52. Lladser A, Mougiakakos D, Tufvesson H, Ligtenberg MA, Quest AFG, Kiessling R. DAI (DLM-1/ZBP1) as a genetic adjuvant for DNA vaccines that promotes effective antitumor CTL immunity. Mol Ther. (2011) 19:594-601. doi: $10.1038 / \mathrm{mt} .2010 .268$
53. Sun F, Zhang YB, Liu TK, Gan L, Yu FF, Liu Y, et al. Characterization of fish IRF3 as an IFN-inducible protein reveals evolving regulation of IFN response in vertebrates. J Immunol. (2010) 185:7573-82. doi: 10.4049/jimmunol.1002401

54. Tsuno T, Mejido J, Zhao T, Schmeisser H, Morrow A, Zoon KC. IRF9 is a key factor for eliciting the antiproliferative activity of IFNalpha. J Immunother. (2009) 32:803-16. doi: 10.1097/CJI.0b013e3181 ad4092

55. Sato M, Suemori H, Hata N, Asagiri M, Ogasawara K, Nakao K. Distinct and essential roles of transcription factors IRF-3 and IRF-7 in response to viruses for IFN- $\alpha / \beta$ gene induction. Immunity. (2000) 13:539-48.

56. Kraus TA, Lau JF, Parisien JP, Horvath CM. A hybrid IRF9-STAT2 protein recapitulates interferon-stimulated gene expression and antiviral response. J Biol Chem. (2003) 278:13033-8. doi: 10.1074/jbc.M2129 72200

57. Zhou Q, Lin H, Wang S, Wang S, Ran Y, Liu Y, et al. The ER-associated protein ZDHHC1 is a positive regulator of DNA virus-triggered, MITA/STINGdependent innate immune signaling. Cell Host Microbe. (2014) 16:450-61. doi: 10.1016/j.chom.2014.09.006

58. Paun A, Pitha PM. The IRF family, revisited. Biochimie. (2007) 89:744-53. doi: 10.1016/j.biochi.2007.01.014

59. Au-Yeung N, Mandhana R, Horvath CM. Transcriptional regulation by STAT1 and STAT2 in the interferon JAK-STAT pathway. JAKSTAT. (2013) 2:e23931. doi: 10.4161/jkst.23931

60. Fink K, Grandvaux N. STAT2 and IRF9: beyond ISGF3. JAKSTAT. (2013) 2:e27521. doi: 10.4161/jkst.27521

61. Wu Z, Wang L, Xu X, Lin G, Mao H, Ran X. Interaction of IRF9 and STAT2 synergistically up-regulates IFN and PKR transcription in Ctenopharyngodon idella. Mol Immunol. (2017) 85:273-82. doi: 10.1016/j.molimm.2017. 03.013

Conflict of Interest Statement: The authors declare that the research was conducted in the absence of any commercial or financial relationships that could be construed as a potential conflict of interest.

Copyright (c) $2019 \mathrm{Xu}, \mathrm{Li}, \mathrm{Wu}, \mathrm{Li}$, Jiang, Liu, Cheng, Mao and Hu. This is an openaccess article distributed under the terms of the Creative Commons Attribution License (CC BY). The use, distribution or reproduction in other forums is permitted, provided the original author(s) and the copyright owner(s) are credited and that the original publication in this journal is cited, in accordance with accepted academic practice. No use, distribution or reproduction is permitted which does not comply with these terms. 